\title{
Visualization of NRAS RNA G-Quadruplex Structures in Cells with an Engineered Fluorogenic Hybridization Probe
}

\author{
Shuo-Bin Chen,${ }^{\dagger}$ Ming-Hao Hu, ${ }^{\dagger}$ Guo-Cai Liu, ${ }^{\dagger}$ Jin Wang,,${ }^{\dagger}$ Tian-Miao Ou, ${ }^{\dagger}$ Lian-Quan Gu, ${ }^{\dagger}$ Zhi-Shu \\ Huang, ${ }^{*}{ }^{\dagger}$ and Jia-Heng Tan $*, \dagger$ \\ † School of Pharmaceutical Sciences, Sun Yat-sen University, Guangzhou 510006, China \\ ¥ Guangzhou Institute of Geochemistry, Chinese Academy of Sciences, Guangzhou 510640, China
}

\section{Table of Contents:}

1. Experimental Section $\quad$ S3

$\begin{array}{ll}\text { 1.1 Synthesis and Characterization } & \text { S3 }\end{array}$

Scheme S1. Synthesis of ISCH-oa1 $\quad$ S3

Scheme S2. Synthesis of GTFH probes $\quad$ S5

Figure S1. ${ }^{1} \mathrm{H}$ NMR spectrum of ISCH-oa1 $\quad$ S6

Figure S2. ${ }^{13} \mathrm{C}$ NMR spectrum of ISCH-oa1 $\quad$ S6

$\begin{array}{ll}\text { Figure S3. HRMS spectrum of ISCH-oa1 } & \text { S7 }\end{array}$

$\begin{array}{ll}\text { Figure S4. HPLC analysis of ISCH-oa1 } & \text { S7 }\end{array}$

Table S1. Characterization of GTFH probes $\quad$ S8

Figure S5. ESI mass spectrum of ISCH-nras1 $\quad$ S8

Figure S6. ESI mass spectrum of ISCH-r1 $\quad$ S8

$\begin{array}{ll}\text { 1.2 CD Studies } & \text { S9 }\end{array}$

1.3 TDS Studies $\quad$ S9

1.4 EMSA Studies $\quad$ S9

$\begin{array}{ll}1.5 \text { Fluorescence Studies } & \text { S9 }\end{array}$

1.6 Preparation of Long RNA Sequence $\quad$ S10

1.7 Cell Cultures and Hybridization Experiment in cells $\quad$ S11

$\begin{array}{ll}\text { 1.8 Protein Extracts and Western Blotting } & \text { S11 }\end{array}$

1.9 High-Content Imaging Studies $\quad$ S12

2. Materials $\quad \mathrm{S} 13$

Table S2. RNA and DNA samples used in the present study $\quad$ S13

3. Other Supporting Table, Spectra and Graphs $\quad$ S14

$\begin{array}{ll}\text { Figure S7. CD spectra of RNAs } & \text { S14 }\end{array}$

$\begin{array}{ll}\text { Figure S8. TDS studies of RNAs } & \text { S14 }\end{array}$

Figure S9. Electrophoresis staining of RNAs by SYBR Gold $\quad$ S15 
Figure S10. Electrophoresis staining of RNAs with ISCH-nras1 by SYBR Gold

Figure S11. Relative fluorescence excitation spectra of ISCH-nras1 with RNAs

Figure S12. Concentration-Dependent fluorescence emission of ISCH-nras1 with

different amounts of G4T25

Figure S13. Fluorescence studies of ISCH-nras1 with different G-quadruplex structures

Figure S14. Fluorescence spectrum of probes with RNAs

Figure S15. Fluorescence studies of ISCH-oa1 with different G-quadruplex structures

Figure S16. Comparisons of the fluorescence emission of ISCH-nras1 and ISCH-oa1

with different G-quadruplex structures

Figure S17. Temperature-Dependent fluorescence of ISCH-nras1 with G4T25

Figure S18. CD melting studies of G4d and GT25/P25c

Figure S19. Quantification of A647-nras1 and ISCH-nras1 spots inside

RNA-transfected cells

Figure S20. Confocal imaging of G4T25-transfected cells stained with ISCH-nras1 and A647-nras1 after RNase A and $H$ treatment

Figure S21. Confocal imaging of G4T25-transfected cells stained with ISCH-nras1 and A647-nras1 upon the addition of complementary strand

Figure S22. Confocal imaging of G4T25-transfected cells stained with ISCH-r1 and ISCH-oa1

Figure S23. Effect of the complementary strand and the G-quadruplex ligand on the visualization of the G4T25 G-quadruplex structure by ISCH-nras1

Figure S24. Evidence of IZCM-7 binding to $N R A S 5^{\prime}$-UTR G-quadruplex in cells

Figure S25. Effect of dsG4T25 on the visualization of the G4T25 G-quadruplex structure by ISCH-nras1

Figure S26. Effect of TERRA on the visualization of the G4T25 G-quadruplex structure by ISCH-nras1

Figure S27. Quantification of spots inside cells transfected with G4T25 stained by various concentrations of A647-nras1 and ISCH-nras1

Figure S28. Quantification of A647-nras1 and ISCH-nras1 spots inside cells transfected with different amount of RNAs

Figure S29. Quantification of the fluorescence intensity inside cells transfected with 5 '-UTR of the NRAS mRNA reporter using high-content imaging platform

Figure S30. Histogram plotting of cell population versus corresponding fluorescence intensity quantified by high-content imaging platform.

Figure S31. Confocal imaging of native cells and cells transfected with 5'-UTR of the $N R A S$ mRNA reporter stained with ISCH-nras1.

\section{References}




\section{Experimental Section}

\subsection{Synthesis and Characterization}

Scheme S1. Synthesis of ISCH-oa1 ${ }^{\text {a }}$
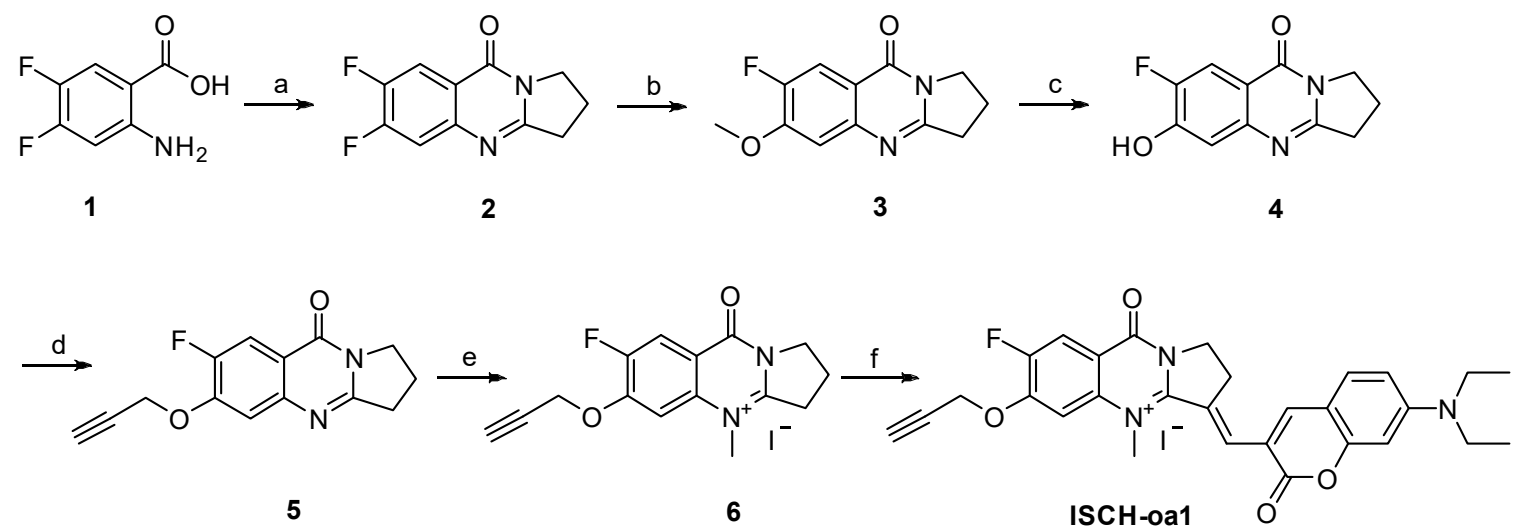

${ }^{a}$ Reagents and conditions: (a) pyrrolidin-2-one, $\mathrm{POCl}_{3}, 110^{\circ} \mathrm{C}, 7 \mathrm{~h}$; (b) $\mathrm{CH}_{3} \mathrm{ONa}, \mathrm{CH}_{3} \mathrm{OH}, 60{ }^{\circ} \mathrm{C}, 24 \mathrm{~h}$; (c) $\mathrm{HBr}, \mathrm{CH}_{3} \mathrm{COOH}$, reflux, $24 \mathrm{~h}$; (d) propargyl bromide, $\mathrm{K}_{2} \mathrm{CO}_{3}$, acetone, $50{ }^{\circ} \mathrm{C}, 15 \mathrm{~h}$; (e) $\mathrm{CH}_{3} \mathrm{I}$, tetramethylene sulfone, $60^{\circ} \mathrm{C}, 20 \mathrm{~h}$; (f) 7-diethylaminocoumarin-3-aldehyde, EtOH, reflux, $12 \mathrm{~h}$.

${ }^{1} \mathrm{H}$ and ${ }^{13} \mathrm{C}$ NMR spectra were recorded by using TMS as the internal standard in DMSO or $\mathrm{CDCl}_{3}$ at 400 $\mathrm{MHz}$ and $100 \mathrm{MHz}$, respectively, with a Bruker BioSpin GmbH spectrometer. Mass spectra (MS) were recorded on a Shimadzu LCMS-2010A instrument with an ESI or ACPI mass selective detector and high resolution mass spectra (HRMS) were recorded on a Shimadzu LCMS-IT-TOF. Flash column chromatography was performed with silica gel (200-300 mesh) purchased from Qingdao Haiyang Chemical Co. Ltd. The purity of the synthesized compound was confirmed to be higher than $95 \%$ by using analytical HPLC performed with a dual pump Shimadzu LC-20 AB system equipped with a Ultimate XB-C18 column $(4.6 \times 250 \mathrm{~mm}, 5 \mu \mathrm{m})$ and eluted with methanol-water $(80: 20)$ containing $0.1 \% \mathrm{TFA}$ at a flow rate of $1.0 \mathrm{~mL} / \mathrm{min}$. All chemicals were purchased from commercial sources unless otherwise specified. All the solvents were of analytical reagent grade and were used without further purification.

Synthesis of 6,7-difluoro-2,3-dihydropyrrolo[2,1-b]quinazolin-9(1H)-one (2): To a mixture of 2-amino-4,5difluorobezoic acid (3.34 g, $19.3 \mathrm{mmol})$ and pyrrolidin-2-one $(3.00 \mathrm{~mL}, 39.5 \mathrm{mmol}), 45 \mathrm{~mL}$ of $\mathrm{POCl}_{3}$ was carefully added at room temperature. The mixture was then stirred at $110{ }^{\circ} \mathrm{C}$ for $7 \mathrm{~h}$. After $\mathrm{POCl}_{3}$ was removed under reduced pressure, the residue was poured into ice water, and then solution of $\mathrm{NaOH}$ was added to make the solution basic. The mixture was extracted with $3 \times 50 \mathrm{~mL}$ portions of $\mathrm{CH}_{2} \mathrm{Cl}_{2}$. The combine organic phase 
was dried over $\mathrm{MgSO}_{4}$ and concentrated under reduced pressure. The crude product was purified by using flash column chromatography with EtOAc/petroleum ether $(1: 4)$ elution to afford a white solid $(2,2.81 \mathrm{~g}$, yield 65\%): ${ }^{1} \mathrm{H}$ NMR (400 MHz, $\left.\mathrm{CDCl}_{3}\right) \delta 8.02(\mathrm{t}, J=9.2 \mathrm{~Hz}, 1 \mathrm{H}), 7.49-7.34(\mathrm{~m}, 1 \mathrm{H}), 4.20(\mathrm{t}, J=7.1 \mathrm{~Hz}, 2 \mathrm{H}), 3.17$ (t, $J=7.8 \mathrm{~Hz}, 2 \mathrm{H}), 2.37-2.23(\mathrm{~m}, 2 \mathrm{H})$. ESI-MS m/z: $223.1[\mathrm{M}+\mathrm{H}]^{+}$.

Synthesis of 7-fluoro-6-methoxy-2,3-dihydropyrrolo[2,1-b]quinazolin-9(1H)-one (3): In the solution of compound 2 (1.00 g, $4.5 \mathrm{mmol})$ in $\mathrm{CH}_{3} \mathrm{OH}(20 \mathrm{~mL}), \mathrm{CH}_{3} \mathrm{ONa}(1.00 \mathrm{~g}, 18.5 \mathrm{mmol})$ was suspended. Then the mixture was stirred at $60{ }^{\circ} \mathrm{C}$ for $24 \mathrm{~h}$ until the starting material disappeared. After that, the solid was removed through filtration, and the remaining solution was concentrated under reduced pressure. Then the crude product was washed by water and further dried to get a pale purple solid $(3,0.90 \mathrm{~g}$, yield $85 \%):{ }^{1} \mathrm{H}$ NMR (400 MHz, $\left.\mathrm{CDCl}_{3}\right) \delta 7.89(\mathrm{~d}, J=11.0 \mathrm{~Hz}, 1 \mathrm{H}), 7.13(\mathrm{~d}, J=7.5 \mathrm{~Hz}, 1 \mathrm{H}), 4.20(\mathrm{t}, J=7.2 \mathrm{~Hz}, 2 \mathrm{H}), 3.98(\mathrm{~s}, 3 \mathrm{H}), 3.17(\mathrm{t}, J=$ $7.9 \mathrm{~Hz}, 2 \mathrm{H}), 2.39-2.23(\mathrm{~m}, 2 \mathrm{H})$. ESI-MS m/z: $235.1[\mathrm{M}+\mathrm{H}]^{+}$.

Synthesis of 7-fluoro-6-hydroxy-2,3-dihydropyrrolo[2,1-b]quinazolin-9(1H)-one (4): Compound 3 (1.00 g, $4.3 \mathrm{mmol})$ was suspended into the solution of $\mathrm{CH}_{3} \mathrm{COOH}(5 \mathrm{ml})$ and $\mathrm{HBr}(47 \%, 5 \mathrm{~mL})$ and then the mixture was stirred at reflux for $24 \mathrm{~h}$. After cooling, the mixture was treated with $\mathrm{NaOH}(\mathrm{aq})$ to reach the $\mathrm{pH}$ of 5 , and the mixture was filtered to get a white solid (4, $0.64 \mathrm{~g}$, yield 68\%): ${ }^{1} \mathrm{H}$ NMR (400 MHz, DMSO- $\left.d_{6}\right) \delta 7.70(\mathrm{~d}, J$ $=11.1 \mathrm{~Hz}, 1 \mathrm{H}), 7.05(\mathrm{~d}, J=8.0 \mathrm{~Hz}, 1 \mathrm{H}), 4.022(\mathrm{t}, J=7.4 \mathrm{~Hz}, 2 \mathrm{H}), 3.03(\mathrm{t}, J=7.8 \mathrm{~Hz}, 2 \mathrm{H}), 2.25-2.07(\mathrm{~m}, 2 \mathrm{H})$. ESI-MS m/z: $221.1[\mathrm{M}+\mathrm{H}]^{+}$.

Synthesis of 7-fluoro-6-(prop-2-yn-1-yloxy)-2,3-dihydropyrrolo[2,1-b]quinazolin-9(1H)-one (5): Propargyl bromide $(0.40 \mathrm{~mL}, 5.0 \mathrm{mmol})$ was added to a solution of $4(1.00 \mathrm{~g}, 4.5 \mathrm{mmol})$ and anhydrous $\mathrm{K}_{2} \mathrm{CO}_{3}$ $(0.69 \mathrm{~g}, 5.0 \mathrm{mmol})$ in $20 \mathrm{~mL}$ acetone. The resulting mixture was heated at $50^{\circ} \mathrm{C}$ for $15 \mathrm{~h}$ until the reaction was complete, and then the solid was filtered away. After that, the remaining solution was concentrated under reduced pressure. Then $50 \mathrm{~mL}$ water was added, and the mixture was then extracted by ethyl acetate $(3 \times 50$ $\mathrm{mL})$. The organic layer was dried over $\mathrm{Na}_{2} \mathrm{SO}_{4}$ and concentrated to get a white solid $(\mathbf{5}, 0.82 \mathrm{~g}$, yield $70 \%) .{ }^{1} \mathrm{H}$ $\operatorname{NMR}\left(400 \mathrm{MHz}, \mathrm{CDCl}_{3}\right) \delta 7.85(\mathrm{~d}, J=10.8 \mathrm{~Hz}, 1 \mathrm{H}), 7.22(\mathrm{~d}, J=7.4 \mathrm{~Hz}, 1 \mathrm{H}), 4.80(\mathrm{~s}, 2 \mathrm{H}), 4.13(\mathrm{t}, J=7.2 \mathrm{~Hz}$ 2H), $3.10(\mathrm{t}, J=7.9 \mathrm{~Hz}, 2 \mathrm{H}), 2.52(\mathrm{~s}, 1 \mathrm{H}), 2.29-2.15(\mathrm{~m}, 2 \mathrm{H})$. ESI-MS m/z: $259.1[\mathrm{M}+\mathrm{H}]^{+}$.

Synthesis of 7-fluoro-4-methyl-9-oxo-6-(prop-2-yn-1-yloxy)-1,2,3,9-tetrahydropyrrolo[2,1-b]quinazolin4-ium (6): A solution of $5(0.50 \mathrm{~g}, 1.9 \mathrm{mmol})$ in tetramethylene sulfone $(2.0 \mathrm{~mL})$ was treated with $\mathrm{CH}_{3} \mathrm{I}(1.0$ 
$\mathrm{mL}, 16.0 \mathrm{mmol})$. The mixture was heated at $60{ }^{\circ} \mathrm{C}$ for $20 \mathrm{~h}$. After cooling, the mixture was filtered, and the crude product was washed with anhydrous ether and dried under vacuum to afford the product as a white solid (6, 0.52 g, yield 67\%). ${ }^{1} \mathrm{H}$ NMR (400 MHz, DMSO- $\left.d_{6}\right) \delta 8.15(\mathrm{~d}, J=10.1 \mathrm{~Hz}, 1 \mathrm{H}), 7.71(\mathrm{~d}, J=6.3 \mathrm{~Hz}, 1 \mathrm{H})$, $5.29(\mathrm{~s}, 2 \mathrm{H}), 4.30(\mathrm{t}, J=6.7 \mathrm{~Hz}, 2 \mathrm{H}), 4.00(\mathrm{~s}, 3 \mathrm{H}), 3.81(\mathrm{~s}, 1 \mathrm{H}), 3.70(\mathrm{t}, J=7.3 \mathrm{~Hz}, 2 \mathrm{H}), 2.40-2.27(\mathrm{~m}, 2 \mathrm{H})$. ESI-MS m/z: $273.1[\mathrm{M}-\mathrm{I}]^{+}$.

Synthesis of (E)-3-((7-(diethylamino)-2-oxo-2H-chromen-3-yl)methylene)-7-fluoro-4-methyl-9-oxo-6(prop-2-yn-1-yloxy)-1,2,3,9-tetrahydropyrrolo[2,1-b]quinazolin-4-ium (ISCH-oa1): A mixture of 6 (0.50 g, $1.2 \mathrm{mmol}), 7-N, N$-diethylaminocoumarin-3-aldehyde $(0.36 \mathrm{~g}, 1.5 \mathrm{mmol})$, and EtOH $(20 \mathrm{~mL})$ was stirred at reflux for $12 \mathrm{~h}$. After cooling to room temperature, the solution was removed under reduced pressure. The crude product was purified by using flash column chromatography with $\mathrm{CH}_{3} \mathrm{OH} / \mathrm{CH}_{2} \mathrm{Cl}_{2}$ (1: 50) elution to afford brownish black solid (7, $0.56 \mathrm{~g}$, yield 71\%): ${ }^{1} \mathrm{H}$ NMR (400 MHz, DMSO- $\left.d_{6}\right) \delta 8.30(\mathrm{~s}, 1 \mathrm{H}), 8.12(\mathrm{~d}, J=10.2$ $\mathrm{Hz}, 1 \mathrm{H}), 7.84(\mathrm{~s}, 1 \mathrm{H}), 7.65-7.75(\mathrm{~m}, 2 \mathrm{H}), 6.86(\mathrm{~d}, J=9.1 \mathrm{~Hz}, 1 \mathrm{H}), 6.64(\mathrm{~s}, 1 \mathrm{H}), 5.30(\mathrm{~s}, 2 \mathrm{H}), 4.35-4.19(\mathrm{~m}$, $5 \mathrm{H}), 3.83(\mathrm{~s}, 1 \mathrm{H}), 3.59-3.44(\mathrm{~m}, 4 \mathrm{H}), 3.39-3.31(\mathrm{~m}, 2 \mathrm{H}), 1.16(\mathrm{t}, J=6.8 \mathrm{~Hz}, 6 \mathrm{H}) .{ }^{13} \mathrm{C}$ NMR $(100 \mathrm{MHz}$, DMSO- $\left.d_{6}\right) \delta 160.36,159.39,156.86,156.26,152.55,151.64,151.12,145.14,139.04,138.82,131.71,126.83$, $113.23,112.98,112.87,110.30,108.37,105.19,96.39,80.22,77.29,58.03,46.64,44.46,41.26,27.67,12.38$. Purity: 97\% by HPLC. HRMS (ESI): calcd for $[\mathrm{M}-\mathrm{I}]^{+}\left(\mathrm{C}_{29} \mathrm{H}_{27} \mathrm{FN}_{3} \mathrm{O}_{4}{ }^{+}\right)$500.1980, found 500.1973.

Scheme S2. Synthesis of GTFH probes ${ }^{\text {a }}$
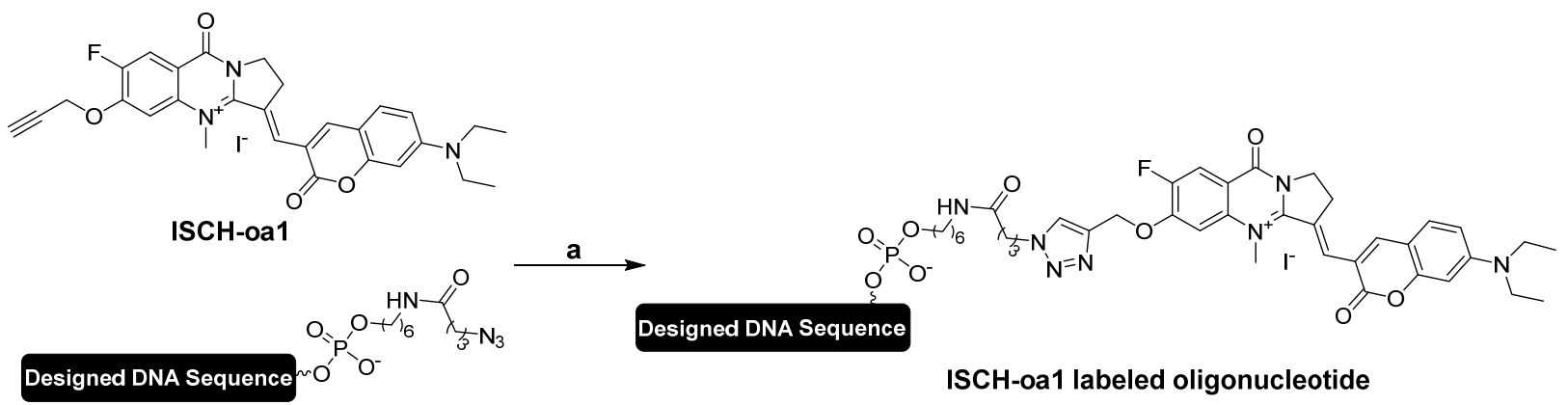

Azido-modified oligonucleotide

${ }^{a}$ Reagents and conditions: (a) water, sodium ascorbate, copper sulfate, $37^{\circ} \mathrm{C}, 24 \mathrm{~h}$.

General Synthesis of GTFH probes: ISCH-oa1 (1 mM) and azido-modified DNA oligonucleotide ( $0.05 \mathrm{mM})$ were mixed in water $(200 \mu \mathrm{L})$ containing fresh sodium ascorbate $(1.2 \mathrm{mM})$, copper sulfate $(0.6 \mathrm{mM})$ was stirred at reflux for $24 \mathrm{~h}$ at $37^{\circ} \mathrm{C}$. The purity was determined by using RP-HPLC-UV and mass spectrometry. 


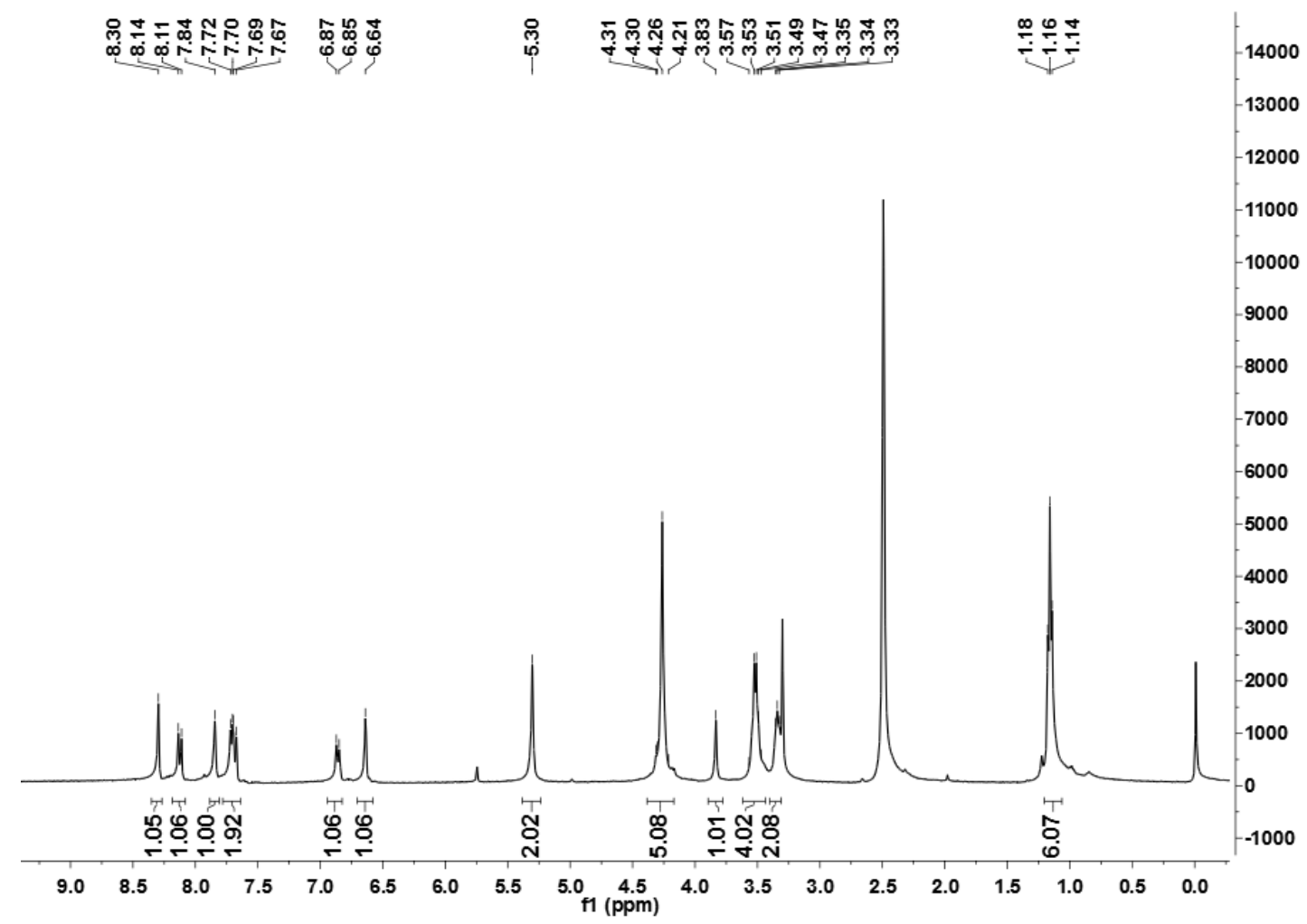

Figure S1. ${ }^{1}$ H NMR spectrum of ISCH-oa1.

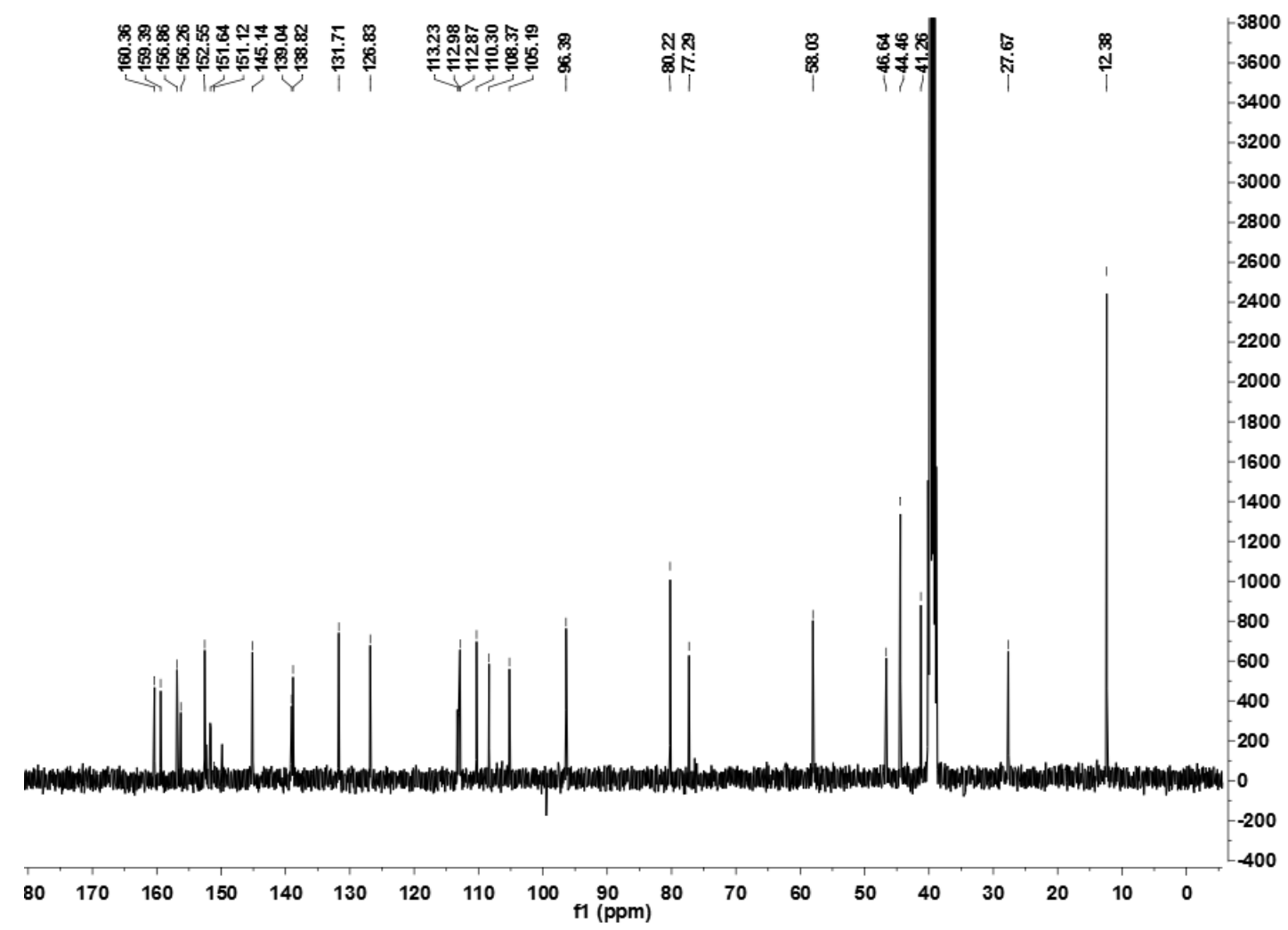

Figure S2. ${ }^{13} \mathrm{C}$ NMR spectrum of ISCH-oa1. 

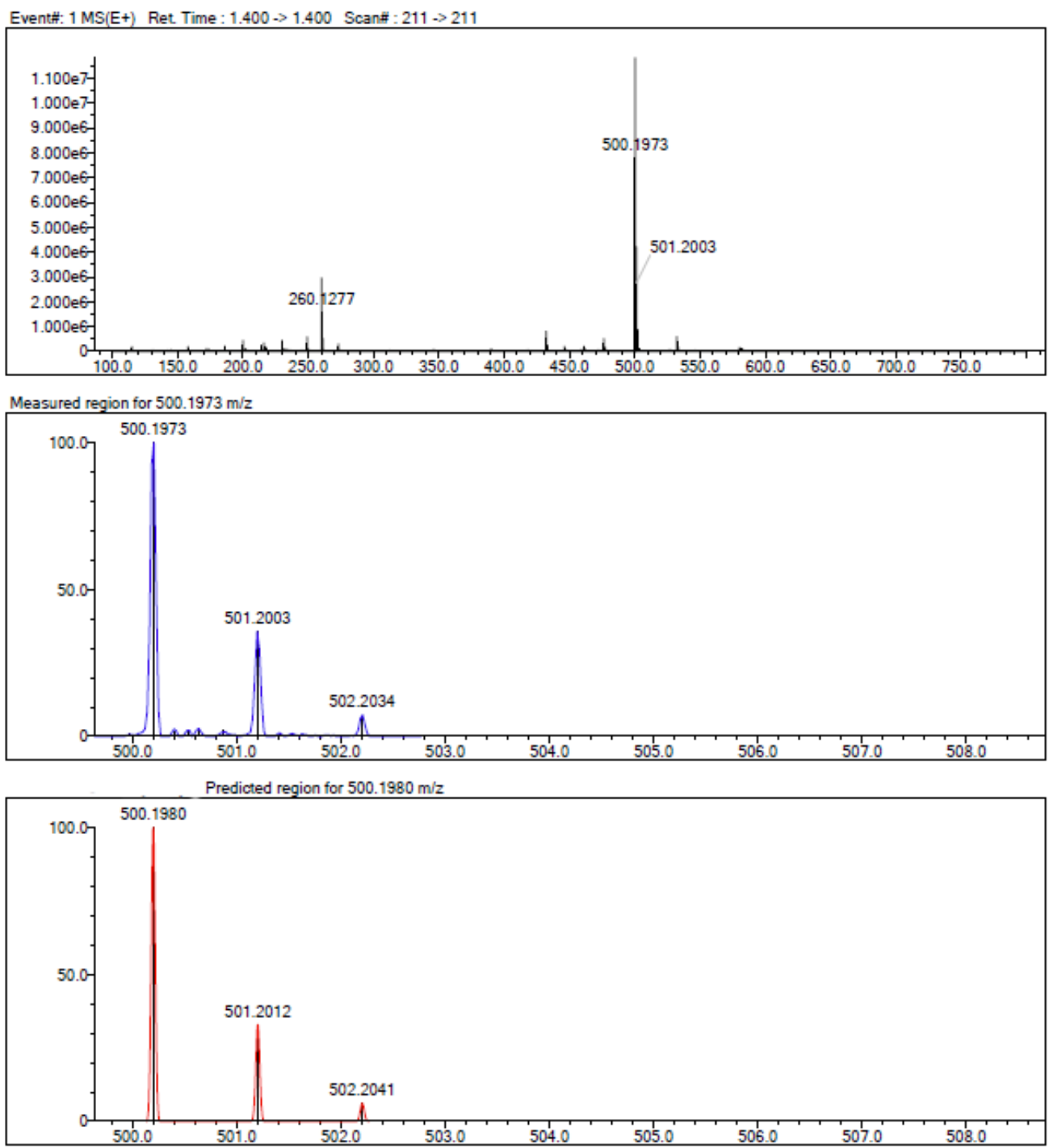

Figure S3. HRMS spectrum of ISCH-oa1.

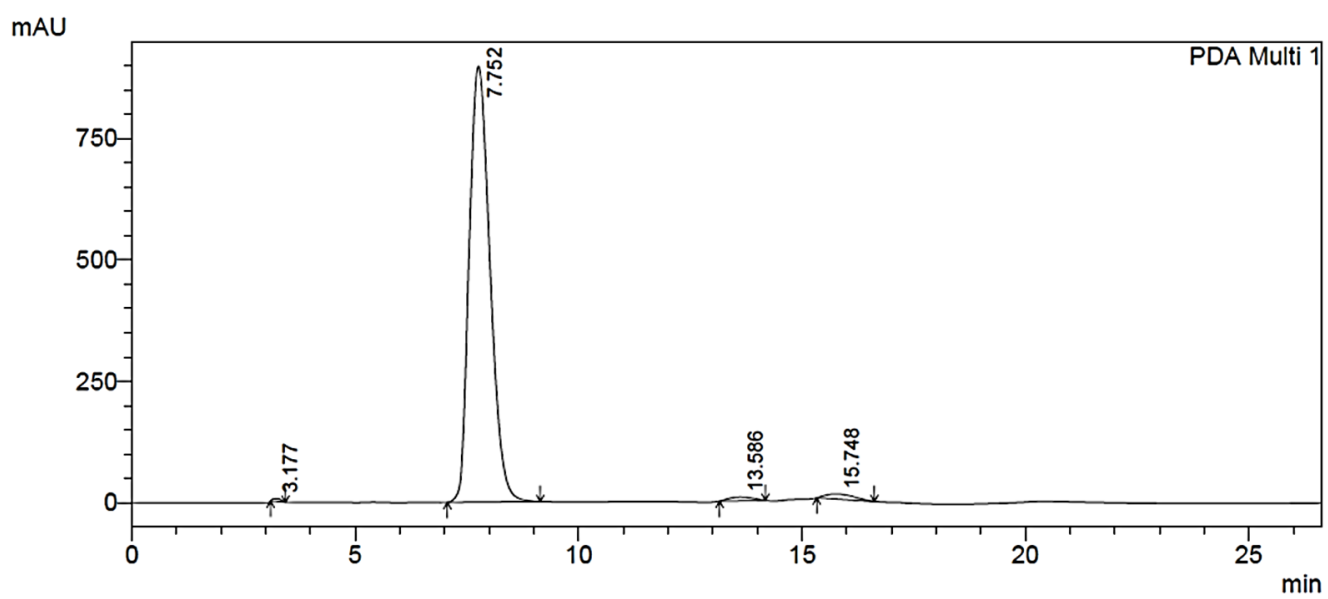

Figure S4. HPLC analysis of ISCH-oa1. 
Table S1. Characterization of GTFH probes.

\begin{tabular}{llcc}
\hline Name & Sequences & Target MS & Observed MS \\
\hline ISCH-nras1 & 5'-d[ACCACGAGTCATGCGGCAGGCCGCA]-3'-ISCH-oa1 & 8454.6 & 8451.6 \\
ISCH-r1 & 5'-d[ATCGACTACGCTTCACTACACCCTA]-3'-ISCH-oa1 & 8298.5 & 8295.6 \\
\hline
\end{tabular}

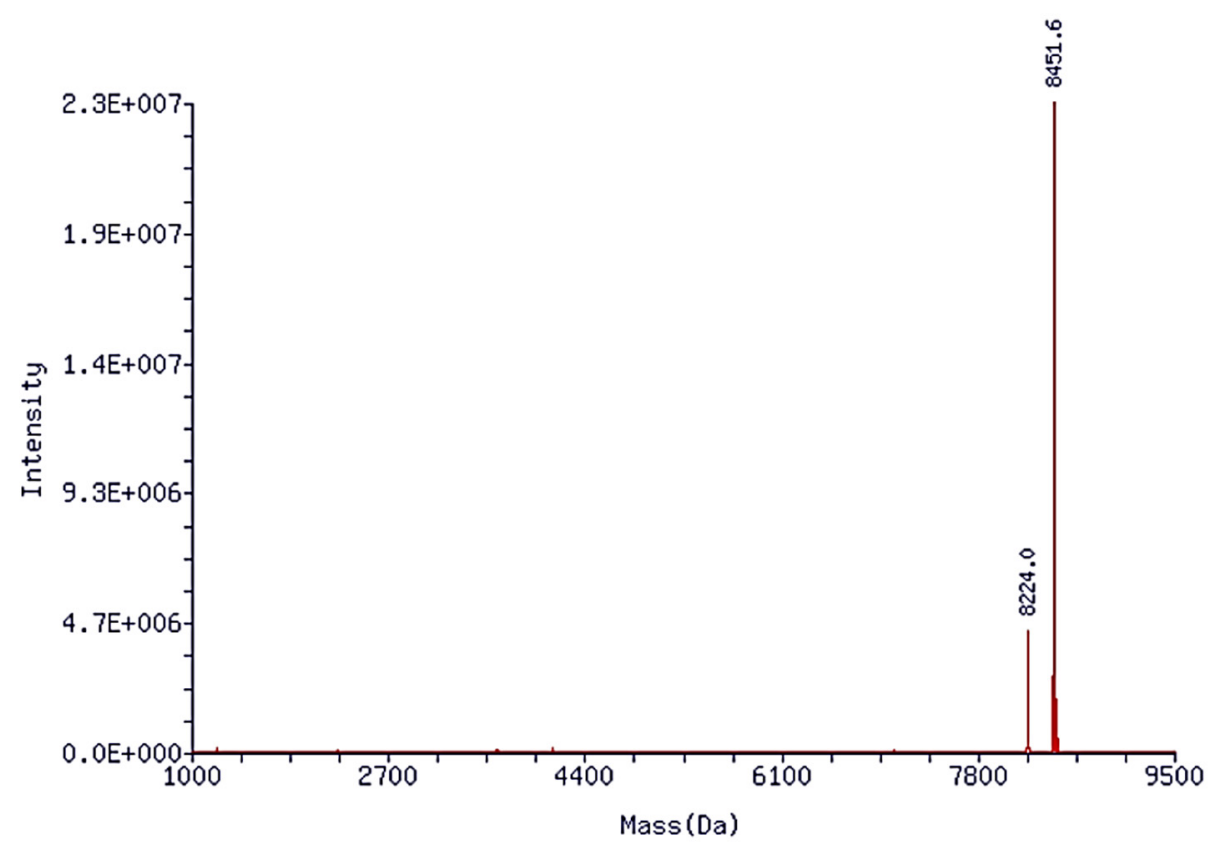

Figure S5. ESI mass spectrum of ISCH-nras1.

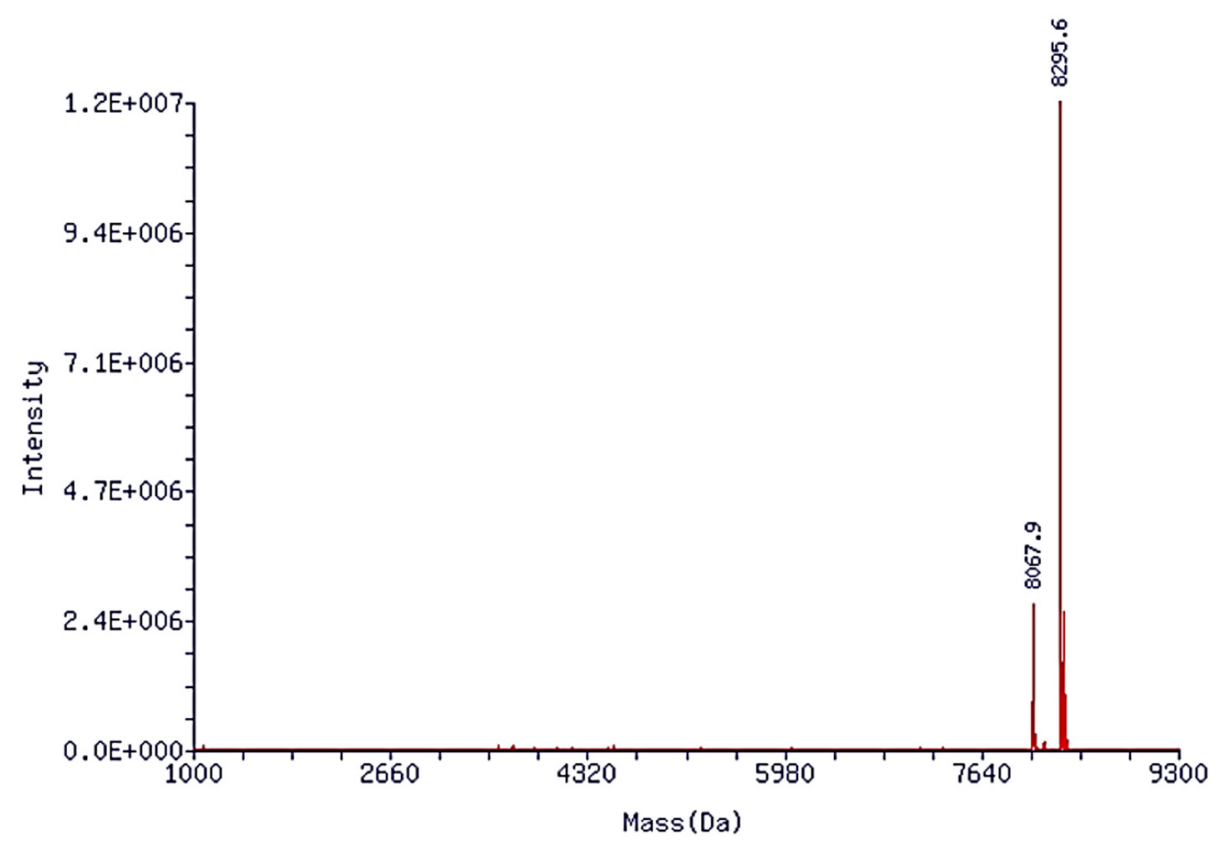

Figure S6. ESI mass spectrum of ISCH-r1. 


\subsection{Studies}

Circular dichroism (CD) studies were performed on a Chirascan circular dichroism spectrophotometer (Applied Photophysics, UK). A quartz cuvette with a $1 \mathrm{~cm}$ path length was used for the recording of spectra over a wavelength range of 230-330 nm with a $1 \mathrm{~nm}$ bandwidth, $1 \mathrm{~nm}$ step size and time of $0.5 \mathrm{~s}$ per point. All oligonucleotides were annealed in relevant buffer by heating to $95{ }^{\circ} \mathrm{C}$ for $5 \mathrm{~min}$, followed by gradual cooling to room temperature. CD melting was performed at a fixed concentration of different nucleic acid $(1 \mu \mathrm{M})$, either with or without a fixed concentration $(5 \mu \mathrm{M})$ of IZCM-7 in Tris-HCl buffer (10 mM, pH 7.2) with $100 \mathrm{mM}$ $\mathrm{KCl}$. The data was recorded at intervals of $2.5^{\circ} \mathrm{C}$ over a range of $25-95^{\circ} \mathrm{C}$, with a heating rate of $1.0{ }^{\circ} \mathrm{C} / \mathrm{min}$. A buffer baseline was collected in the same cuvette and was subtracted from the sample spectra. Final analysis of the data was conducted using Origin 7.0 (OriginLab Corp.).

\subsection{TDS Studies}

Thermal difference spectrum (TDS) studies were performed on a UV-2450 spectrophotometer (Shimadzu, Japan) using $1 \mathrm{~cm}$ path length quartz cuvette. All RNA oligonucleotides were diluted from stock to final concentration $(1 \mu \mathrm{M})$ in Tris-HCl buffer $(10 \mathrm{mM}, \mathrm{pH}$ 7.2) with $100 \mathrm{mM} \mathrm{KCl}$. All samples were annealed by heating at $95^{\circ} \mathrm{C}$ for $5 \mathrm{~min}$, gradually cooled to room temperature and measured after $24 \mathrm{~h}$. UV-Vis spectra were recorded at 25 and $95{ }^{\circ} \mathrm{C}$. A 10 min equilibration period at each measurement was allowed to ensure homogeneous sample temperature. TDS spectra were calculated by subtracting the spectrum at $25^{\circ} \mathrm{C}$ from the spectrum at $95^{\circ} \mathrm{C}$.

\subsection{Electrophoretic Mobility Shift Assay (EMSA) Studies}

Different oligonucleotides were loaded onto a $20 \%$ bisacrylamide gel in $1 \times \mathrm{TBE}$ buffer containing $100 \mathrm{mM}$ $\mathrm{KCl}$ and were electrophoresed at $4{ }^{\circ} \mathrm{C}$. Oligonucleotides were stained by SYBR Gold and visualized under UV light and photographed using AlphaImager EC (Protein Simple).

\subsection{Fluorescence Studies}

Fluorescence studies were performed on QuantaMaster 400 Intensity Based Spectrofluorometer (PTI, USA). A quartz cuvette with $3 \mathrm{~mm} \times 3 \mathrm{~mm}$ path length was used for the spectra recorded at $1 \mathrm{~nm}$ excitation and emission slit widths unless otherwise specified. Temperature-dependent fluorescence studies were performed on Chirascan circular dichroism spectrophotometer (Applied Photophysics, UK) equipped with a fluorometer accessory and a Peltier holder. The data was recorded at intervals of $5{ }^{\circ} \mathrm{C}$ over a range of $25-95{ }^{\circ} \mathrm{C}$, with a heating rate of $1.0^{\circ} \mathrm{C} / \mathrm{min}$. 


\subsection{Preparation of Long RNA Sequence}

DNA fragments containing 5'-UTR sequence in NRAS mRNA and two restriction site, Nhe I/EcoR V were prepared by overlap PCR. The fragments were then inserted in the Nhe I site of the psiCHECK-2 vector (Promega, USA). Fragments containing 5'-UTR sequence were located between an upstream T7 promoter and a downstream EcoR V restriction site. Linear DNA with blunt end was prepared by cleavage of EcoR V site with Anza ${ }^{\mathrm{TM}} 26$ Eco32I (Thermo Fisher Scientific, USA). The target RNAs were prepared by in vitro transcription following the Transcript Aid T7 High Yield Transcription Kit (Thermo Fisher Scientific, USA). The sequence of full-length NRAS 5'-UTR RNA fragments were list below.

UTR-full:

GCUAGCGAAACGUCCCGUGUGGGAGGGGCGGGUCUGGGUGCGGCCUGCCGCAUGACUCGUGG UUCGGAGGCCCACGUGGCCGGGGCGGGGACUCAGGCGCCUGGGGCGCCGACUGAUUACGUAG CGGGCGGGGCCGGAAGUGCCGCUCCUUGGUGGGGGCUGUUCAUGGCGGUUCCGGGGUCUCCA ACAUUUUUCCCGGCUGUGGUCCUAAAUCUGUCCAAAGCAGAGGCAGUGGAGCUUGAGGUUCU UGCUGGUGUGAAGAU

UTR-mutG:

GCUAGCGAAACGUCCCGUGUAAAAAAAGCGAGUCUGGGUGCGGCCUGCCGCAUGACUCGUGG UUCGGAGGCCCACGUGGCCGGGGCGGGGACUCAGGCGCCUGGGGCGCCGACUGAUUACGUAG CGGGCGGGGCCGGAAGUGCCGCUCCUUGGUGGGGGCUGUUCAUGGCGGUUCCGGGGUCUCCA ACAUUUUUCCCGGCUGUGGUCCUAAAUCUGUCCAAAGCAGAGGCAGUGGAGCUUGAGGUUCU UGCUGGUGUGAAGAU

UTR-delG:

GCUAGCGAAACGUCCCGUGCGGCCUGCCGCAUGACUCGUGGUUCGGAGGCCCACGUGGCCGG GGCGGGGACUCAGGCGCCUGGGGCGCCGACUGAUUACGUAGCGGGCGGGGCCGGAAGUGCCG CUCCUUGGUGGGGGCUGUUCAUGGCGGUUCCGGGGUCUCCAACAUUUUUCCCGGCUGUGGUC CUAAAUCUGUCCAAAGCAGAGGCAGUGGAGCUUGAGGUUCUUGCUGGUGUGAAGAU UTR-mT25:

GCUAGCGAAACGUCCCGUGUGGGAGGGGCGGGUCUGGGUACAACCUACCACAUAACUCAUAA UUCGGAGGCCCACGUGGCCGGGGCGGGGACUCAGGCGCCUGGGGCGCCGACUGAUUACGUAG CGGGCGGGGCCGGAAGUGCCGCUCCUUGGUGGGGGCUGUUCAUGGCGGUUCCGGGGUCUCCA 


\subsection{Cell Cultures and Hybridization Experiment in cells}

The SiHa cells were grown in DMEM media containing $10 \%$ fetal bovine serum at $37{ }^{\circ} \mathrm{C}$, with $5 \% \mathrm{CO}_{2}$ atmosphere. Cells were seeded in glass bottom 96-well plate (MatTek) and grew overnight. Oligonucleotide transfections were performed using $50 \mathrm{nM}$ RNA oligonucleotides and Lipofectamine 3000 Transfection Reagent (Invitrogen, USA) for over $3 \mathrm{~h}$. Cells were fixed with 4\% paraformaldehyde in DEPC-PBS at room temperature for $15 \mathrm{~min}$. After rinsing with DEPC-PBS, cells were permeabilized in $0.5 \%$ TritonX100/DEPC/PBS at $37^{\circ} \mathrm{C}$ for $30 \mathrm{~min}$. After rinsing with $2 \mathrm{X}$ SSC, probes were diluted at $0.3 \mu \mathrm{M}$ in hybridization buffer (4XSSC, 0.5 mM EDTA, 10\% dextran sulfate, 30\% deionized-formamide in DEPC-H2O) and applied to the cells. Hybridization was done at $37{ }^{\circ} \mathrm{C}$ overnight. After hybridization, cells were washed in $2 \mathrm{XSSC}$ for 15 min twice and subsequently stained with $\left(0.5 \mu \mathrm{g} \cdot \mathrm{mL}^{-1}\right)$ DAPI for 15 min at $37^{\circ} \mathrm{C}$. For the RNase A treatment, cells were incubated with 200 units $\cdot \mathrm{mL}^{-1}$ RNase A before hybridization at $37{ }^{\circ} \mathrm{C}$ for $1 \mathrm{~h}$. For the RNase $\mathrm{H}$ treatment, cells were incubated with 200 units $\cdot \mathrm{mL}^{-1} \mathrm{RNase} \mathrm{H}$ after hybridization at $37^{\circ} \mathrm{C}$ for $1 \mathrm{~h}$. Digital images were recorded using a LSM 710 laser scanning confocal microscope with a $63 \times$ objective lens, and analyzed with Imaris software (Bitplane Corp.).

\subsection{Protein Extracts and Western Blotting}

After $24 \mathrm{~h}$ treatment of IZCM-7, SiHa cells were harvested from each well. The cells were washed once with PBS and lysed with extraction buffer (50 mM glucose, $25 \mathrm{mM}$ Tris-HCl, $\mathrm{pH} \mathrm{8,} 10 \mathrm{mM}$ EDTA, $1 \mathrm{mM}$ PMSF) at $4{ }^{\circ} \mathrm{C}$ for $30 \mathrm{~min}$. The lysed cells were centrifuged at $10,000 \mathrm{rpm}$ at $4{ }^{\circ} \mathrm{C}$ for $5 \mathrm{~min}$. The supernatant was transferred into another tube and the concentration of protein was calculated via BCA method. After boiled for $5 \mathrm{~min}$ at $95{ }^{\circ} \mathrm{C}$ with addition of loading buffer $(50 \mathrm{mM}$ Tris- $\mathrm{HCl}, \mathrm{pH}$ 6.8, $6 \mathrm{M}$ urea, $6 \%$ 2-mercaptoethanol, $3 \%$ SDS, $0.003 \%$ bromophenol blue), $20 \mu \mathrm{g}$ of protein was loaded for each lane and resolved by SDS-PAGE and then transferred to a microporous polyvinylidene difluoride (PVDF) membrane and analyzed by Western blotting. Primary antibodies used for western blotting in this study were GAPDH (Beyotime Biotechnology: AF0006), NRAS (Aviva Systems Biology: OAEB02340). Secondary antibodies used were horseradish peroxidase-conjugated anti-mouse (Cell Signaling Technology: 7076S) or anti-rabbit (Cell Signaling Technology: 7074S). Protein bands were visualized using chemiluminescence substrate. 


\subsection{High-Content Imaging Studies}

The SiHa cells were grown in DMEM media containing $10 \%$ fetal bovine serum at $37{ }^{\circ} \mathrm{C}$, with $5 \% \mathrm{CO}_{2}$ atmosphere. Cells were seeded in glass bottom 96-well plate (MatTek) and grew overnight. pRNAT-U6.1/Neo vector (GenScript, USA) with DNA fragment containing 5'-UTR sequence in NRAS mRNA were transfected by Lipofectamine 3000 Transfection Reagent (Invitrogen, USA) for $24 \mathrm{~h}$. Cells were fixed with 4\% paraformaldehyde in DEPC-PBS at room temperature for $15 \mathrm{~min}$. After rinsing with DEPC-PBS, cells were permeabilized in $0.5 \%$ TritonX-100/DEPC/PBS at $37{ }^{\circ} \mathrm{C}$ for $30 \mathrm{~min}$. After rinsing with $2 \mathrm{X}$ SSC, probes were diluted at $1 \mu \mathrm{M}$ in hybridization buffer (4XSSC, $0.5 \mathrm{mM}$ EDTA, $10 \%$ dextran sulfate, 30\% deionizedformamide in DEPC-H2O) and applied to the cells. Hybridization was done at $37{ }^{\circ} \mathrm{C}$ overnight. After hybridization, cells were washed in 2XSSC for $15 \mathrm{~min}$ twice and subsequently stained with $\left(0.5 \mu \mathrm{g} \cdot \mathrm{mL}^{-1}\right)$ DAPI for $15 \mathrm{~min}$ at $37{ }^{\circ} \mathrm{C}$. The Cellomics ArrayScan Vti (Thermo Fisher Scientific, USA) high-content imaging platform was used for the quantification of the fluorescence signal in cells. The high-content analysis automatically focused in the fluorescence channel of DAPI and captured the channel of ISCH-nras1 with exposed time for $2 \mathrm{~s}$ in the cytoplasm. Each sample contained about 10000 cells and three parallel experiments were performed. 


\section{Materials}

Table S2. RNA and DNA samples used in the present study.

\begin{tabular}{ll}
\hline Name & Oligonucleotide Sequence \\
\hline G4T25 & 5'-r[UGUGGGAGGGGCGGGUCUGGGUGCGGCCUGCCGCAUGACUCGUGGU]-3' \\
G4T25-mg1 & 5'-r[UGUAAGAGAAGCGAGUCUGAGUGCGGCCUGCCGCAUGACUCGUGGU]-3' \\
G4T25-mg2 & 5'-r[UGUAAAAAAAGCGAGUCUGAGUGCGGCCUGCCGCAUGACUCGUGGU]-3' \\
G4T25-mt1 & 5'-r[UGUGGGAGGGGCGGGUCUGGGUACAACCUACCACAUAACUCAUAAU]-3' \\
GT25 & 5'-r[GUGCGGCCUGCCGCAUGACUCGUGGU]-3' \\
G4d & 5'-r[UGUGGGAGGGGCGGGUCUGGG]-3' \\
TERRA & 5'-r[GGGUUAGGGUUAGGGUUAGGG]-3' \\
FAM-G4T25 & 5'-FAM-r[UGUGGGAGGGGCGGGUCUGGGUGCGGCCUGCCGCAUGACUCGUGGU]-3' \\
G4c & 5'-d[CCCAGACCCGCCCCTCCCACA]-3' \\
P25c & 5'-d[ACCACGAGTCATGCGGCAGGCCGCA]-3' \\
PU22 & 5'-d[TGAGGGTGGGTAGGGTGGGTAA]-3' \\
HTG22 & 5'-d[AGGGTTAGGGTTAGGGTTAGGG]-3' \\
HRAS & 5'-d[TCGGGTTGCGGGCGCAGGGCACGGGCG]-3' \\
A647-nras1 & 5'-d[ACCACGAGTCATGCGGCAGGCCGCA]-3'-AlexaFluor647 \\
Azido-nras1 & 5'-d[ACCACGAGTCATGCGGCAGGCCGCA]-3'-Azido \\
Azido-r1 & 5'-d[ATCGACTACGCTTCACTACACCCTA]-3'-Azido \\
dsG4T25 & 5'-d[TGTGGGAGGGGCGGGTCTGGGTGCGGCCTGCCGCATGACTCGTGGT]-3' \\
\hline
\end{tabular}

All oligonucleotides used in this study were purchased from Invitrogen (China), TaKaRa (China) and Integrated DNA Technologies (USA). SYBR Gold was purchased from Thermo Fisher Scientific (USA). All the oligonucleotides were dissolved in relevant buffer. Their concentrations were determined from the absorbance at $260 \mathrm{~nm}$, respectively on the basis of respective molar extinction coefficients using NanoDrop 1000 Spectrophotometer (Thermo Fisher Scientific, USA). To obtain G-quadruplex formation, oligonucleotides were annealed in relevant buffer containing $\mathrm{KCl}$ by heating to $95^{\circ} \mathrm{C}$ for $5 \mathrm{~min}$, followed by gradual cooling to room temperature. IZCM-7 was prepared according to published procedures. ${ }^{1}$ Stock solutions of compounds $(10 \mathrm{mM})$ were dissolved in DMSO and stored at $-80^{\circ} \mathrm{C}$. Further dilutions of samples to working concentrations were made with relevant buffer immediately prior to use. 


\section{Other Supporting Table, Spectra and Graphs}
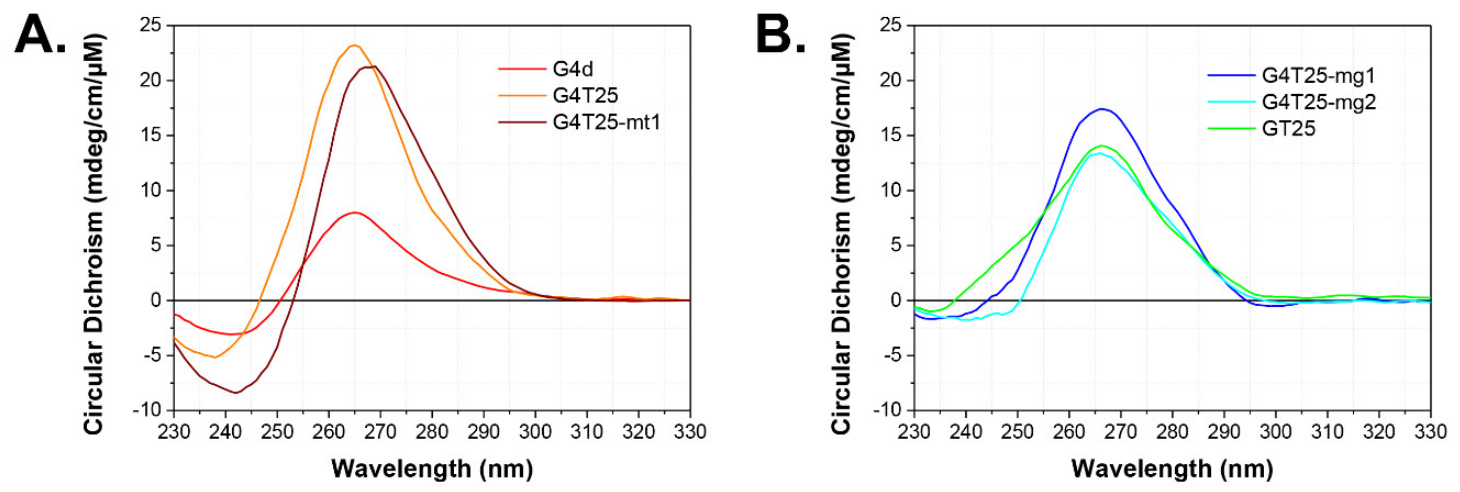

Figure S7. CD spectra of $1 \mu \mathrm{M}$ RNAs in $10 \mathrm{mM}$ Tris-HCl buffer, $100 \mathrm{mM} \mathrm{KCl}, \mathrm{pH}$ 7.2. (A) RNAs with G-rich sequences. (B) RNAs with mutation or deletion of G-rich sequences. The CD profiles of the RNAs with G-rich sequences (G4T25, G4T25-mt1 and G4d) showed a positive peak at around $265 \mathrm{~nm}$, and a significant negative peak at around $240 \mathrm{~nm}$. These peaks were typical signatures of G-quadruplex structures. ${ }^{2}$
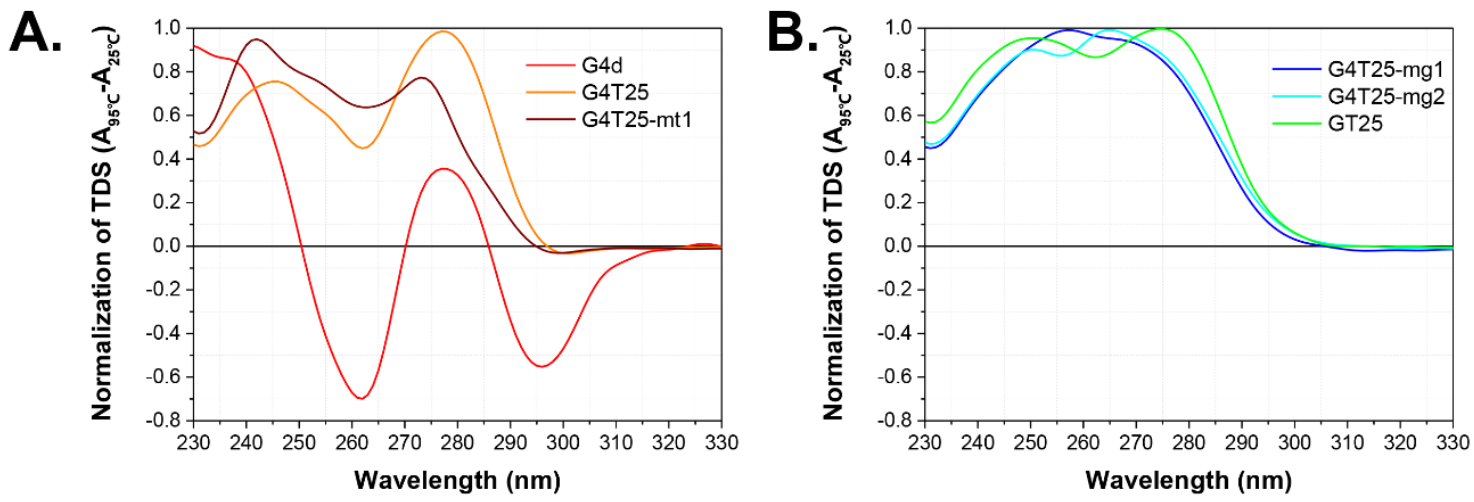

Figure S8. TDS studies of $1 \mu \mathrm{M}$ RNAs in $10 \mathrm{mM}$ Tris-HCl buffer, $100 \mathrm{mM} \mathrm{KCl,} \mathrm{pH} \mathrm{7.2.} \mathrm{(A)} \mathrm{RNAs} \mathrm{with} \mathrm{G-}$ rich sequences. (B) RNAs with mutation or deletion of G-rich sequences. TDS studies were obtained by recording the UV absorbance spectra of the unfolded and folded states at temperatures above and below the melting temperature. The TDS profiles of the RNAs with G-rich sequences (G4T25, G4T25-mt1 and G4d) showed two positive peaks at $240 \mathrm{~nm}$ and $275 \mathrm{~nm}$, and a negative peak at $297 \mathrm{~nm}$. These peaks were typical signatures of G-quadruplex structures. ${ }^{3}$ By contrast, TDS profiles of sequences G4T25-mg1, G4T25-mg2 and GT25 were quite different. They could not form G-quadruplex structures. 


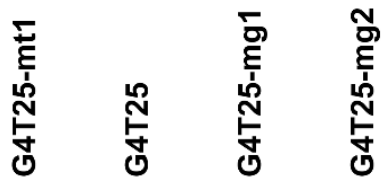

\section{G-quadruplex -}

Single strand

Figure S9. Electrophoresis staining of RNAs by SYBR Gold.

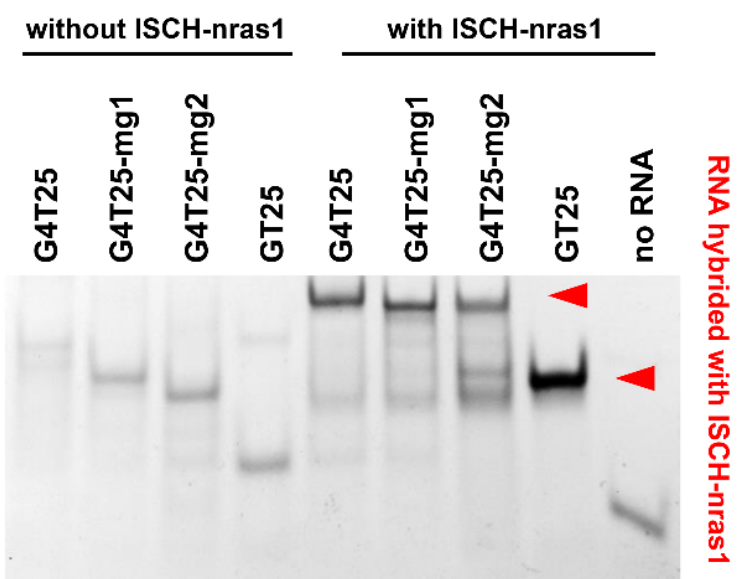

Figure S10. Electrophoresis staining of RNAs with or without ISCH-nras1 by SYBR Gold.



Figure S11. Relative fluorescence excitation spectra of $1 \mu \mathrm{M}$ ISCH-nras1 in $10 \mathrm{mM}$ Tris-HCl buffer, $100 \mathrm{mM}$ $\mathrm{KCl}, \mathrm{pH} 7.2$, with and without RNAs. Intensity ratio of emission at $650 \mathrm{~nm}\left(\mathrm{~F}_{\text {ISCH-nras1 with RNAs }} / \mathrm{F}_{\text {ISCH-nras1 alone }}\right)$ were employed to determine the optimal excitation wavelength for distinguishing G4T25 from other RNAs to the greatest extent possible. Obviously, $630 \mathrm{~nm}$ was the best excitation wavelength. Besides, $630 \mathrm{~nm}$ was also suitable for the laser scanning confocal microscope. Thus, $630 \mathrm{~nm}$ was chosen as the excitation wavelength for the fluorescence and cell imaging studies. 

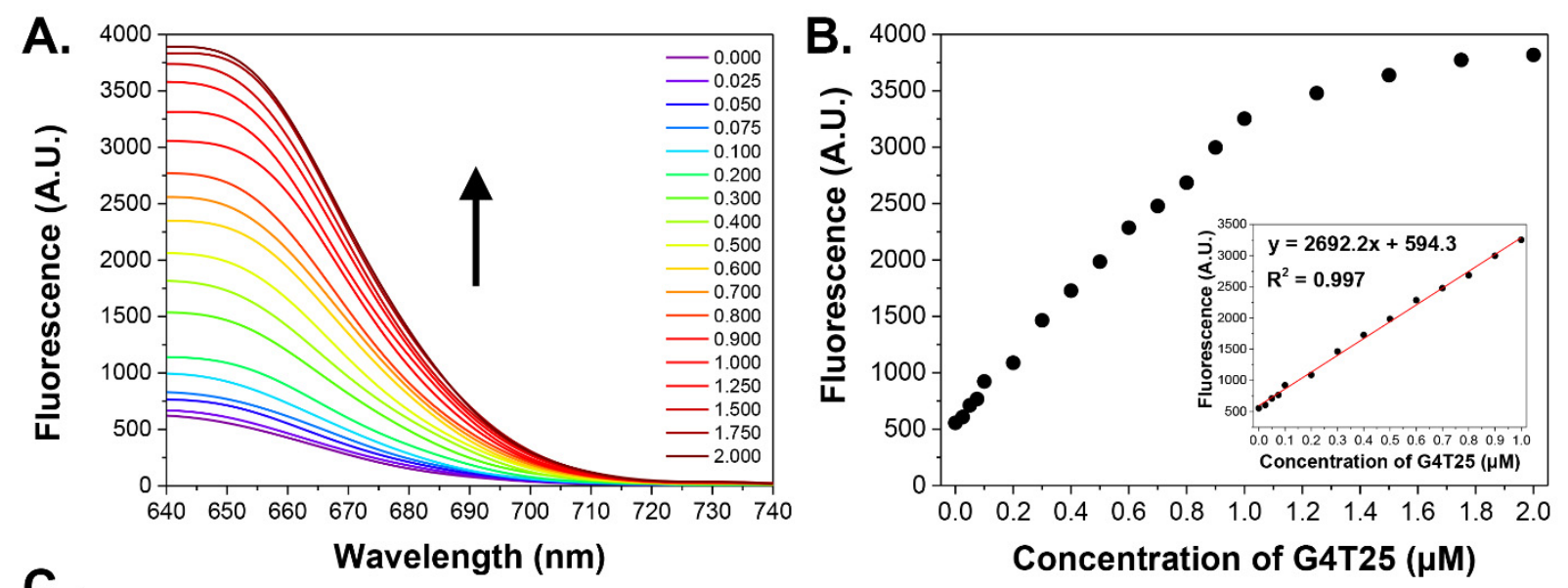

C.

Fluorescence Intensity of ISCH-nras1 with Different Amounts of G4T25

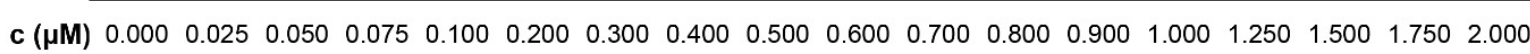

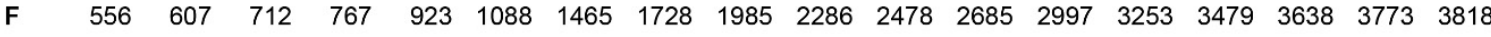

Figure S12. Concentration-Dependent fluorescence emission of $1 \mu \mathrm{M}$ ISCH-nras1 with different amounts of

G4T25 in $10 \mathrm{mM}$ Tris-HCl buffer, $100 \mathrm{mM} \mathrm{KCl}, \mathrm{pH} 7.2$, excited at $630 \mathrm{~nm}$. (A) Fluorescence spectra of $1 \mu \mathrm{M}$

ISCH-nras1 with different amounts of G4T25. (B) The fluorescence emission change of $1 \mu \mathrm{M}$ ISCH-nras1 at $650 \mathrm{~nm}$ against different amounts of G4T25. Linear fit equation for calculating detection limit of ISCH-nras1 for G4T25 was plotted in the inner panel. The detection limit was then calculated on the basis of the equation "detection limit $=K \times S_{b} / m$ ". ${ }^{1}$ The $K$ value is generally taken to be 3 according to the IUPAC recommendation. The $S_{b}$ value represents the standard deviation for multiple measurements $(\mathrm{n}=20)$ of blank solution. The $m$ value is the slope of the calibration curve, which is derived from the linear range of ISCH-nras1 fluorescence titration curve with G4T25 and represents the sensitivity of this method. The detection limit of ISCH-nras1 for the RNA G-quadruplex formed by the G4T25 was $0.024 \mu \mathrm{M}$. (C) Fluorescence emission data of $1 \mu \mathrm{M}$ ISCHnras1 with different amounts of G4T25 at $650 \mathrm{~nm}$. 

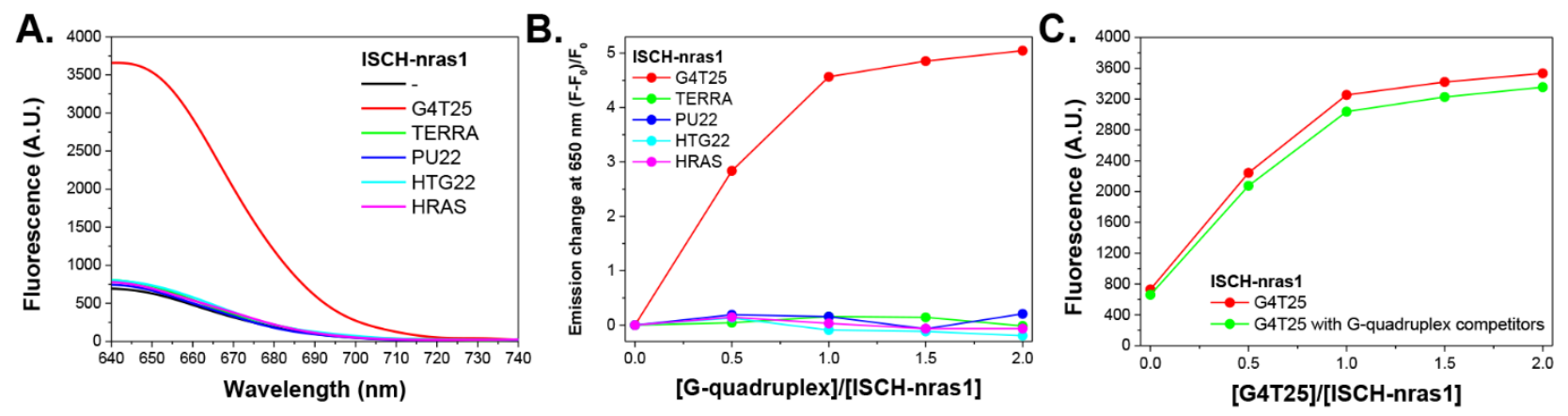

Figure S13. Fluorescence studies of the interactions of ISCH-nras1 with different G-quadruplex structures in $10 \mathrm{mM}$ Tris- $\mathrm{HCl}$ buffer, $100 \mathrm{mM} \mathrm{KCl}, \mathrm{pH} 7.2$, excited at $630 \mathrm{~nm}$. (A) Fluorescence spectrum of $1 \mu \mathrm{M}$ ISCHnras1 with or without $2 \mu \mathrm{M}$ G-quadruplexs. (B) The fluorescence emission change of $1 \mu \mathrm{M}$ ISCH-nras1 at 650 $\mathrm{nm}$ against the ratio of [G-quadruplex]/[ISCH-nras1]. (C) The fluorescence titration of $1 \mu \mathrm{M}$ ISCH-nras1 with the stepwise addition of the G4T25 without and with a mixture of G-quadruplex competitors containing $2 \mu \mathrm{M}$ TERRA, PU22, HTG22 and HRAS, respectively. While adding G4T25 into the solution containing ISCHnras1 and other G-quadruplex structures, the enhanced fluorescence emissions were practically identical to those in the experiment without competitors. These results further confirmed attaching an oligonucleotide to the G-quadruplex probe that could hybridize with a sequence adjacent to the G-rich sequence of interest would improve its selectivity.
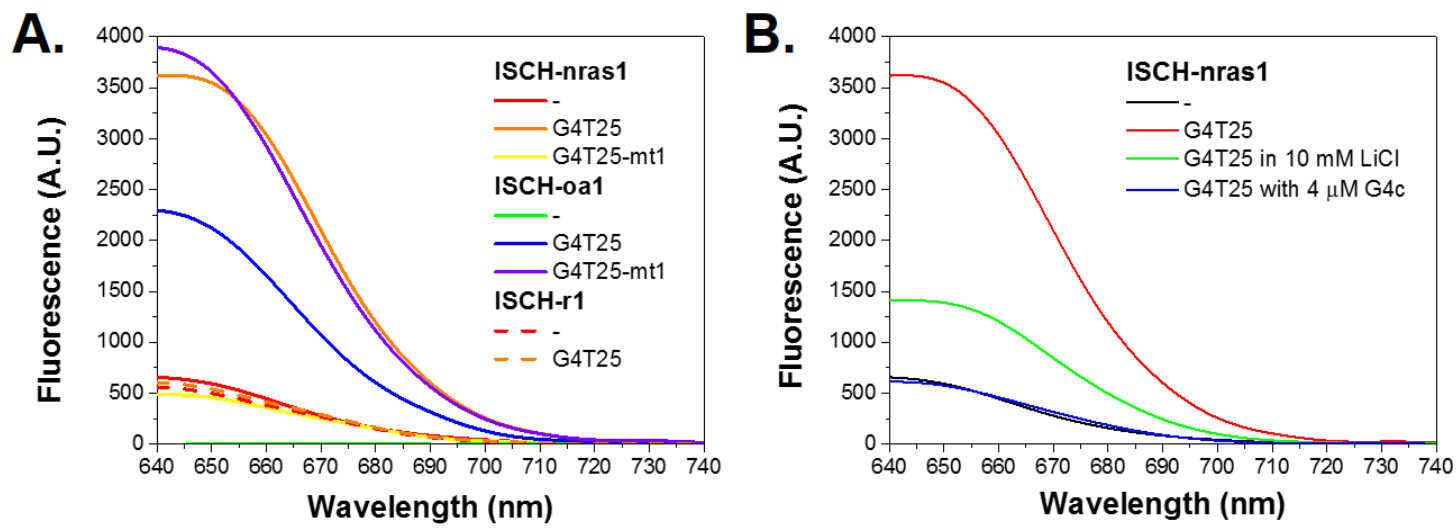

Figure S14. Fluorescence spectrum of $1 \mu \mathrm{M}$ probes with and without RNAs excited at $630 \mathrm{~nm}$. (A) Fluorescence spectra of different probes with or without G4T25, G4T25-mt1 in $10 \mathrm{mM}$ Tris- $\mathrm{HCl}$ buffer, $100 \mathrm{mM} \mathrm{KCl,} \mathrm{pH}$ 7.2. (B) Fluorescence spectra of ISCH-nras1 with or without G4T25 in the present of LiCl or G4c. In the presence of lithium ions or the anti-sense C-rich DNA strand $\mathbf{G 4 c}$, which is complementary strand to the G-rich sequence of G4T25, G-quadruplex structure in G4T25 unwound. 

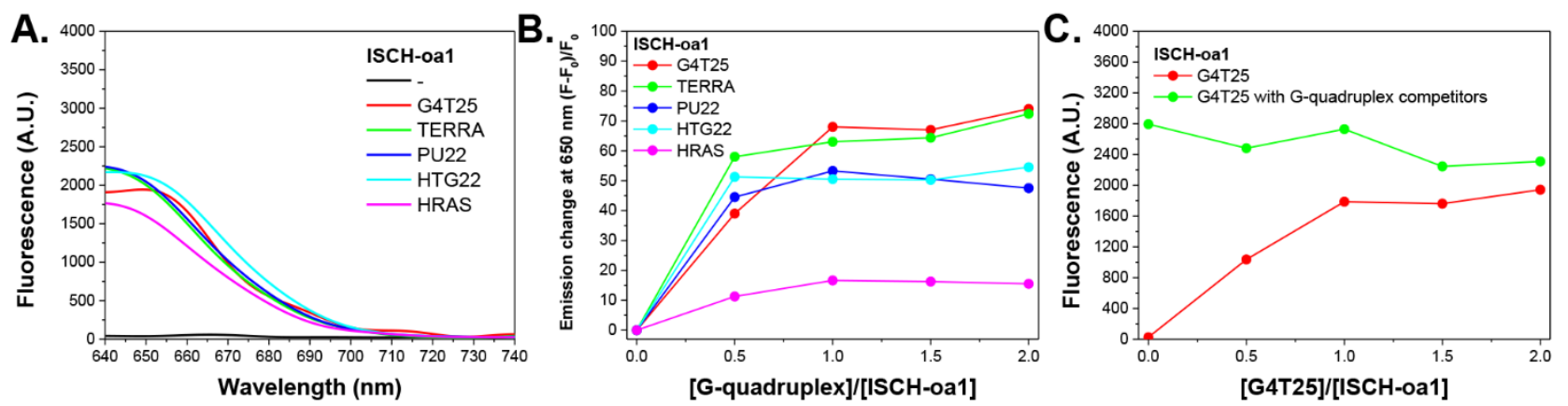

Figure S15. Fluorescence studies of the interactions of ISCH-oa1 with different G-quadruplex structures in 10 $\mathrm{mM}$ Tris-HCl buffer, $100 \mathrm{mM} \mathrm{KCl}, \mathrm{pH} 7.2$, excited at $630 \mathrm{~nm}$. (A) Fluorescence spectrum of $1 \mu \mathrm{M}$ ISCH-oa1 with or without $2 \mu \mathrm{M}$ G-quadruplexs. (B) The fluorescence emission change of $1 \mu \mathrm{M}$ ISCH-oa1 at $650 \mathrm{~nm}$ against the ratio of [G-quadruplex]/[ISCH-oa1]. (C) The fluorescence titration of $1 \mu \mathrm{M}$ ISCH-oa1 with the stepwise addition of the G4T25 without and with a mixture of G-quadruplex competitors containing $2 \mu \mathrm{M}$ TERRA, PU22, HTG22 and HRAS, respectively. The enhanced fluorescence emissions of ISCH-oa1 were greatly affected by the G-quadruplex competitors.

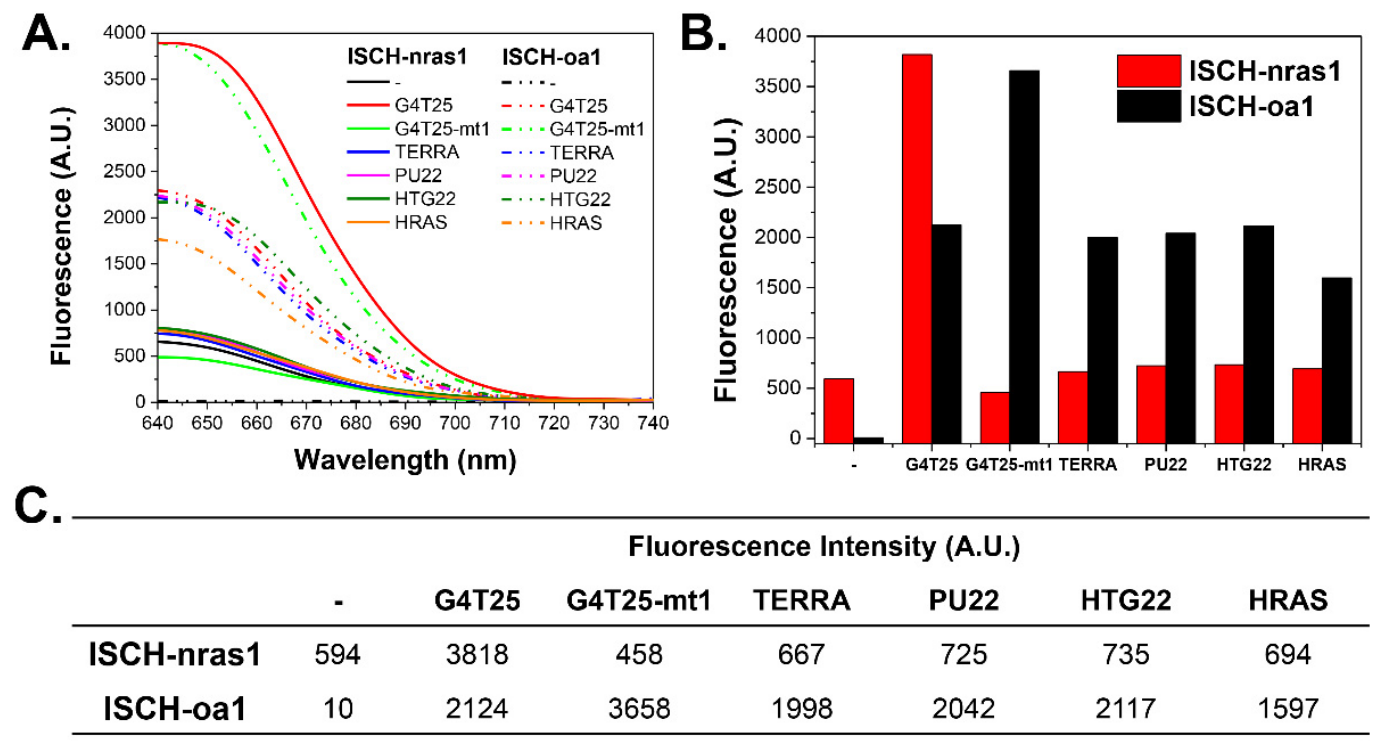

Figure S16. Comparisons of the fluorescence emission of $1 \mu \mathrm{M}$ ISCH-nras1 and ISCH-oa1 without (-) or with $2 \mu \mathrm{M}$ different G-quadruplex structures in $10 \mathrm{mM}$ Tris- $\mathrm{HCl}$ buffer, $100 \mathrm{mM} \mathrm{KCl}, \mathrm{pH}$ 7.2, excited at $630 \mathrm{~nm}$. (A) Fluorescence spectra of $1 \mu \mathrm{M}$ ISCH-nras1 and ISCH-oa1 without (-) or with $2 \mu \mathrm{M}$ different G-quadruplex structures. (B) Fluorescence emission of $1 \mu \mathrm{M}$ ISCH-nras1 and ISCH-oa1 without (-) or with $2 \mu \mathrm{M}$ different G-quadruplex structures at $650 \mathrm{~nm}$. (C) Fluorescence emission data of $1 \mu \mathrm{M}$ ISCH-nras1 and ISCH-oa1 without (-) or with $2 \mu \mathrm{M}$ different G-quadruplex structures at $650 \mathrm{~nm}$. 
A.

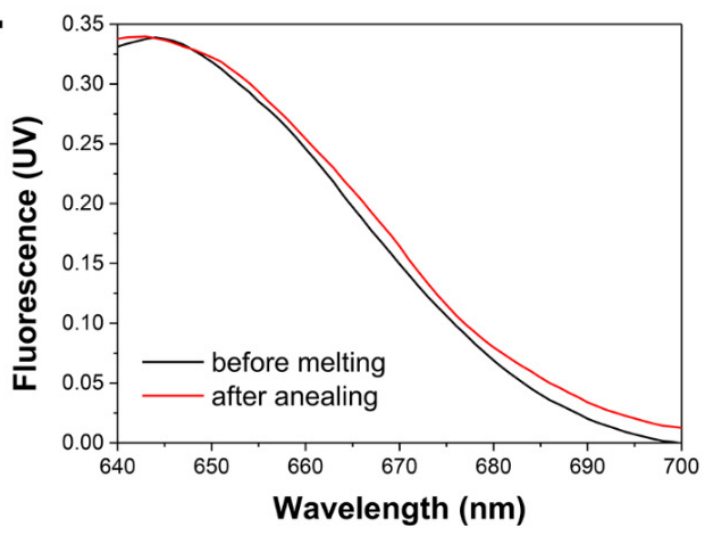

B.

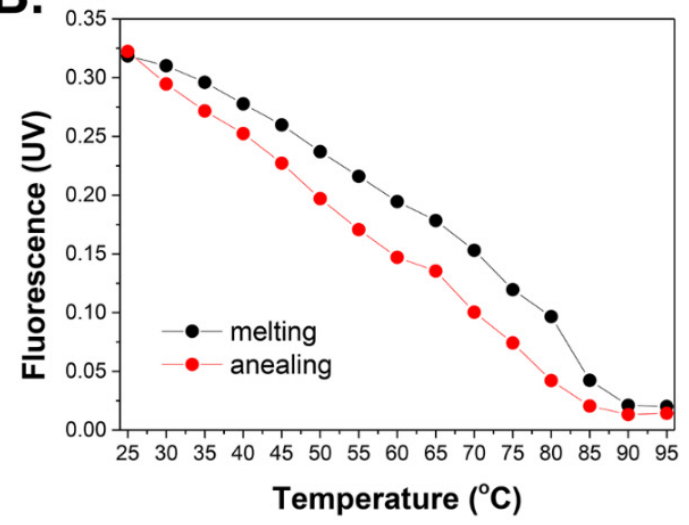

Figure S17. Temperature-Dependent fluorescence studies of ISCH-nras1 with G4T25 in $10 \mathrm{mM}$ Tris-HCl buffer, $100 \mathrm{mM} \mathrm{KCl}, \mathrm{pH} 7.2$, excited at $630 \mathrm{~nm}$. (A) Fluorescence spectrum of $5 \mu \mathrm{M}$ ISCH-nras1 with $5 \mu \mathrm{M}$ G4T25 before melting and after annealing process. (B) Fluorescence intensity of $5 \mu \mathrm{M}$ ISCH-nras1 with 5 $\mu \mathrm{M}$ G4T25 during the melting or annealing process.

A.

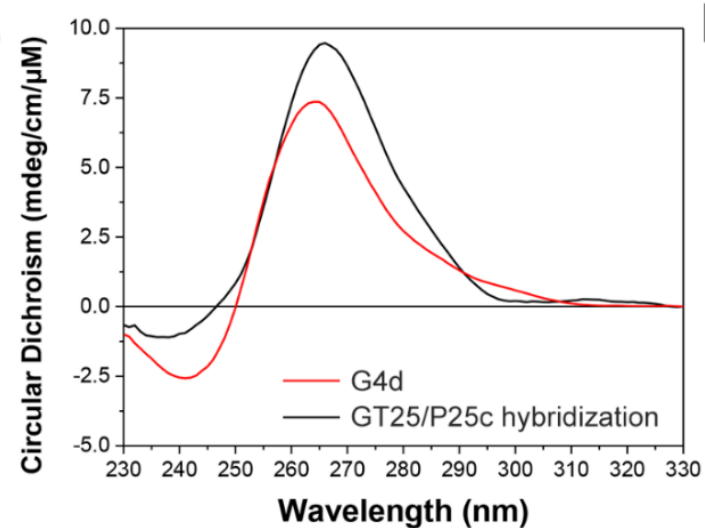

B.

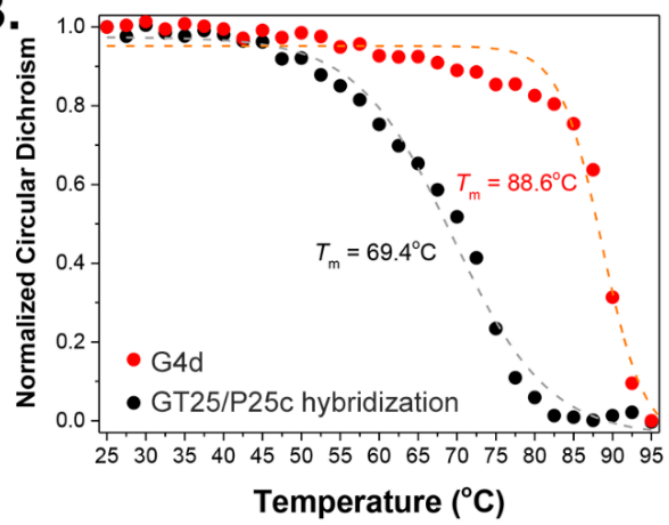

Figure S18. CD melting studies of $1 \mu \mathrm{M}$ RNA G-quadruplex (G4d) and $1 \mu \mathrm{M}$ DNA-RNA hybridization duplex (hybridization of GT25 and P25c) in $10 \mathrm{mM}$ Tris-HCl buffer, $100 \mathrm{mM} \mathrm{KCl}, \mathrm{pH}$ 7.2. (A) CD spectra of the Gquadruplex and duplex structures. (B) Normalized CD signal of the G-quadruplex and duplex structures during melting process. The G-quadruplex in G4d was characterized by the positive peak at $265 \mathrm{~nm}$, and the duplex in GT25/P25c was characterized by the positive peak at $270 \mathrm{~nm}$. The melting point was calculated by the Boltzmann Formula. 


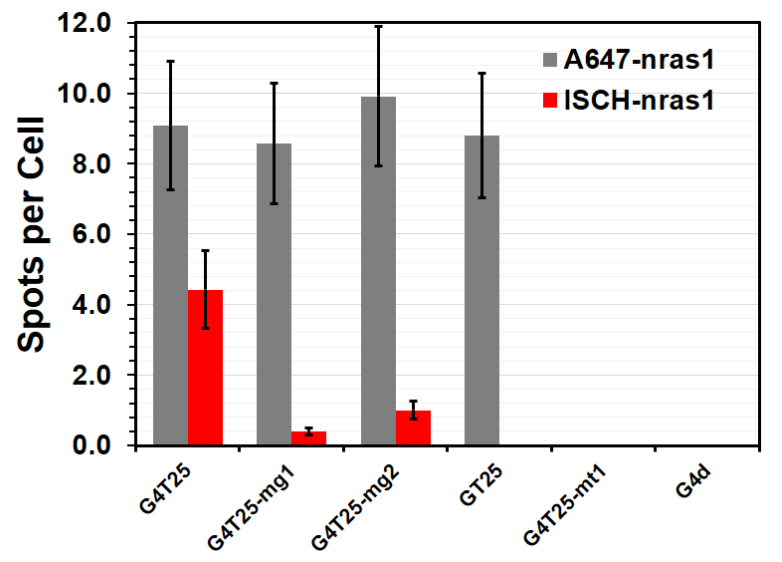

Figure S19. Quantification of A647-nras1 and ISCH-nras1 spots inside cells transfected with RNAs.

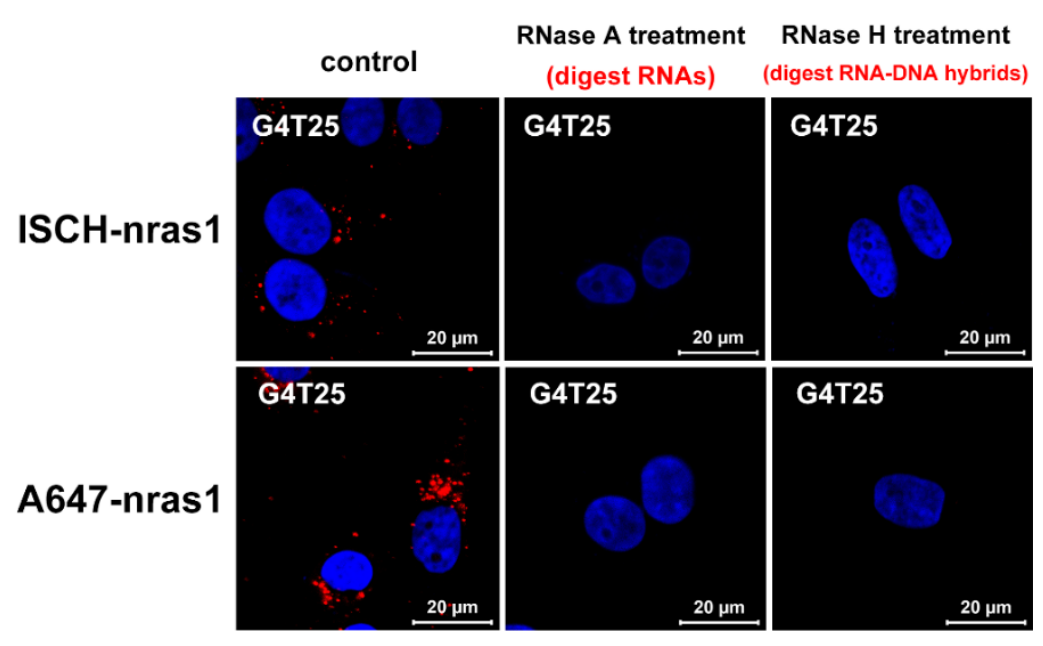

Figure S20. Confocal imaging of G4T25-transfected cells stained with ISCH-nras1 and A647-nras1 after RNase A and $\mathrm{H}$ treatment.

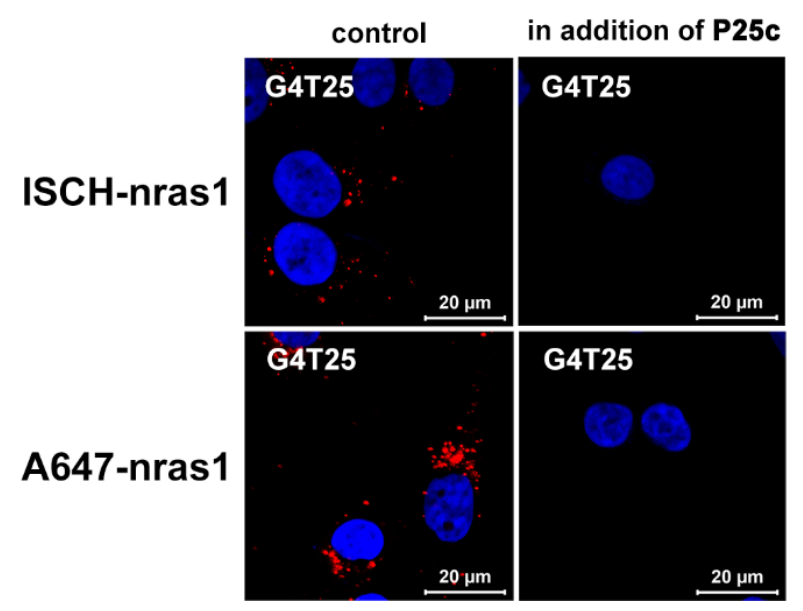

Figure S21. Confocal imaging of G4T25-transfected cells stained with ISCH-nras1 and A647-nras1 upon the addition of a complementary strand P25c to the tail sequence of G4T25 in the staining processes. 

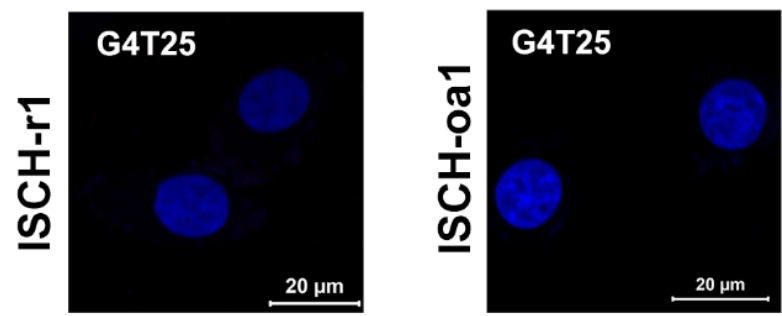

Figure S22. Confocal imaging of G4T25-transfected cells stained with ISCH-r1 and ISCH-oa1.

A.

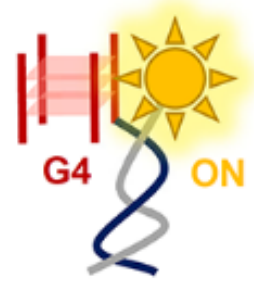

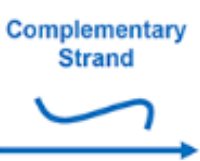
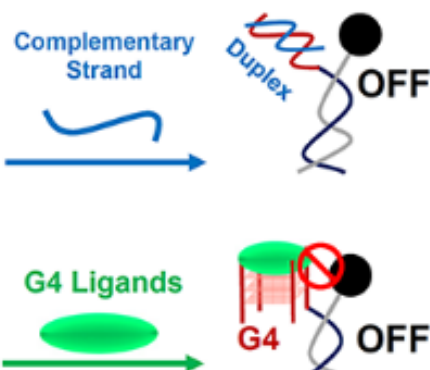

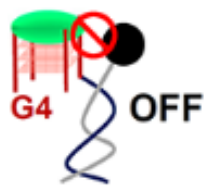

B.

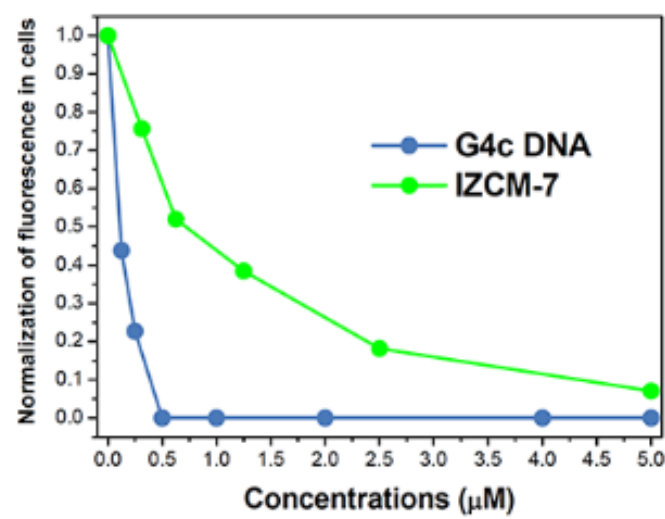

Figure S23. Effect of the complementary strand G4c and the G-quadruplex ligand IZCM-7 on the visualization of the G4T25 G-quadruplex structure by ISCH-nras1. (A) Illustration of the interactions. (B) Change in fluorescence inside the cells upon addition of G4c and IZCM-7.

A.

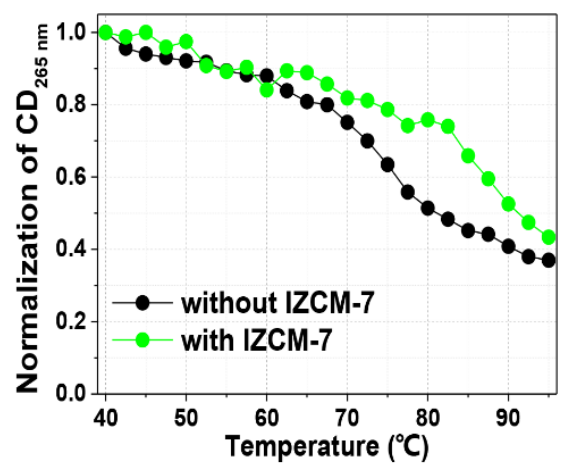

B.

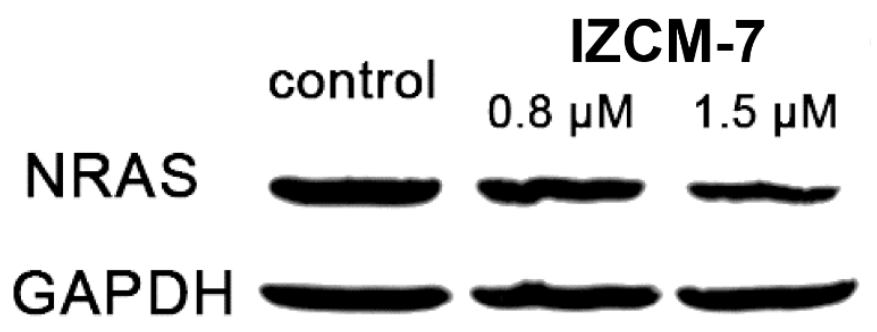

Figure S24. Evidence of IZCM-7 binding to NRAS 5'-UTR G-quadruplex in cells. (A) CD melting curves of RNA G4T25 with or without IZCM-7. (B) Expression of NRAS protein in SiHa cells with or without IZCM7. 

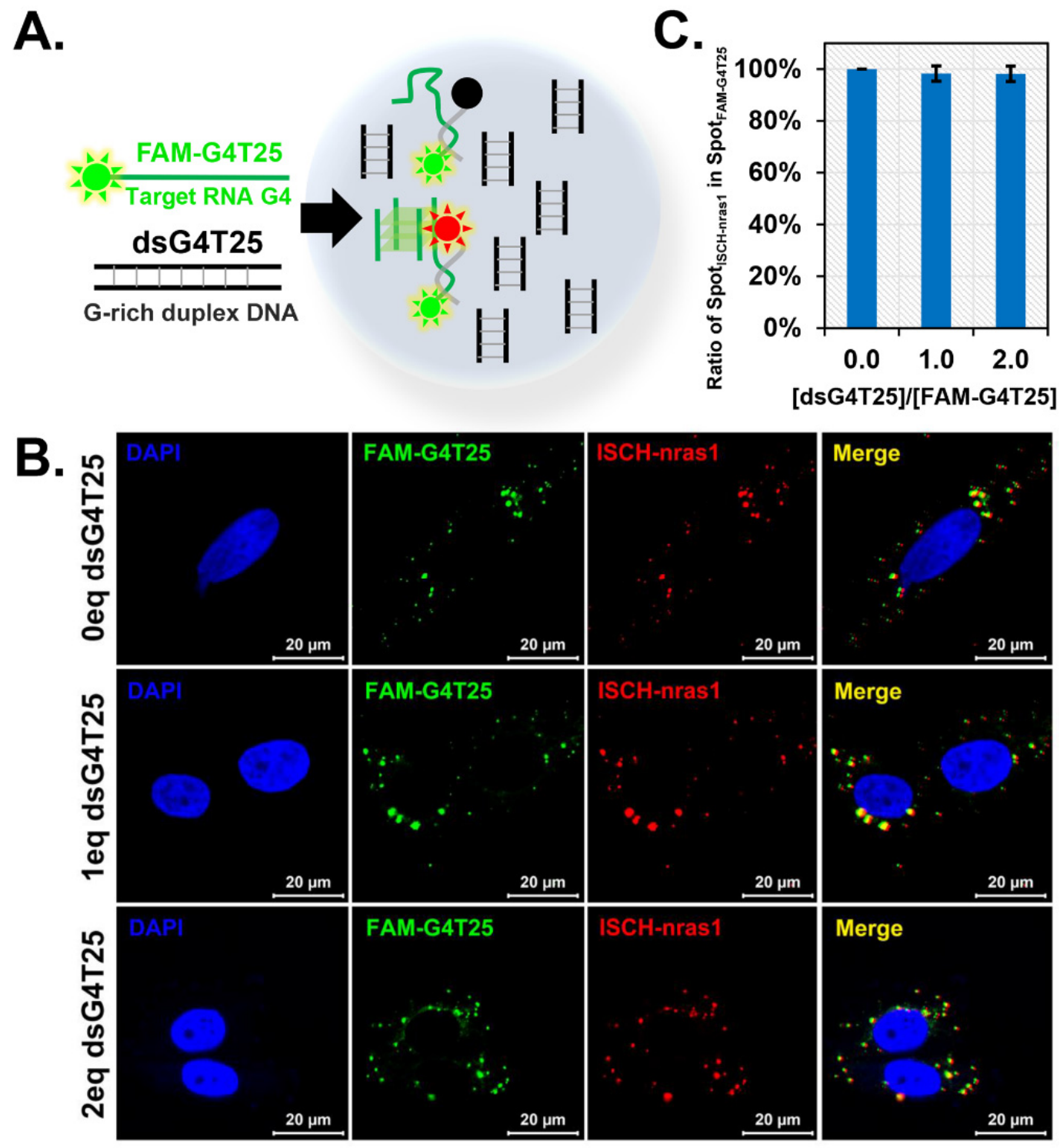

Figure S25. Effect of dsG4T25 on the visualization of the G4T25 G-quadruplex structure by ISCH-nras1. dsG4T25 was a G-rich duplex competitor, whose sequence was identical to G4T25. (A) Illustration of the cotransfection and tracking of the RNAs in cells. (B) Confocal imaging of the effect of dsG4T25 on the visualization of the G4T25 G-quadruplex structure by ISCH-nras1. (C) Quantification of ISCH-nras1 spots inside FAM-G4T25 spots in cells. ${ }^{4}$ 


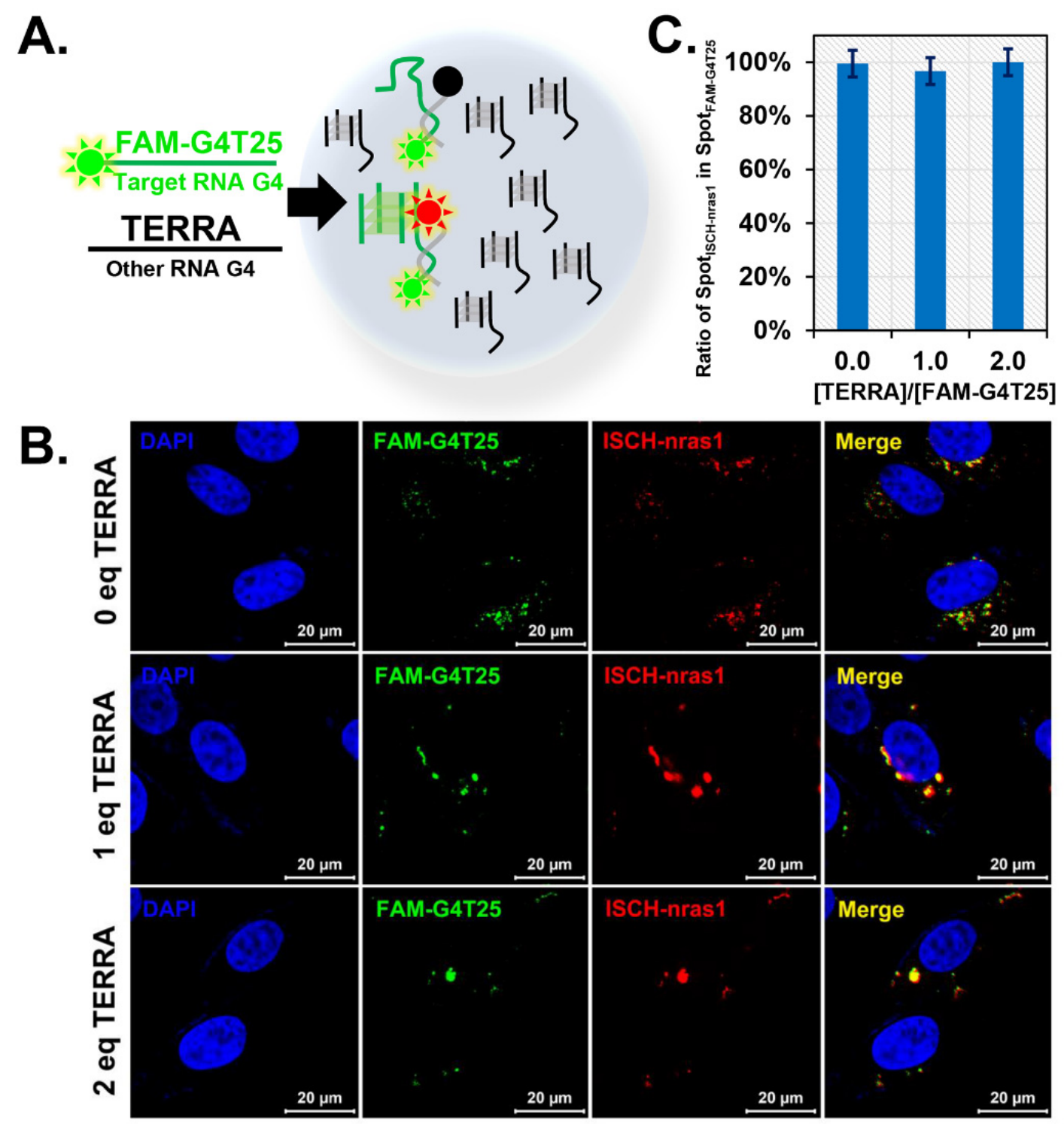

Figure S26. Effect of TERRA on the visualization of the G4T25 G-quadruplex structure by ISCH-nras1. TERRA was a RNA G-quadruplex competitor. (A) Illustration of the co-transfection and tracking of the RNAs in cells. (B) Confocal imaging of the effect of TERRA on the visualization of the G4T25 G-quadruplex structure by ISCH-nras1. (C) Quantification of ISCH-nras1 spots inside FAM-G4T25 spots in cells. 


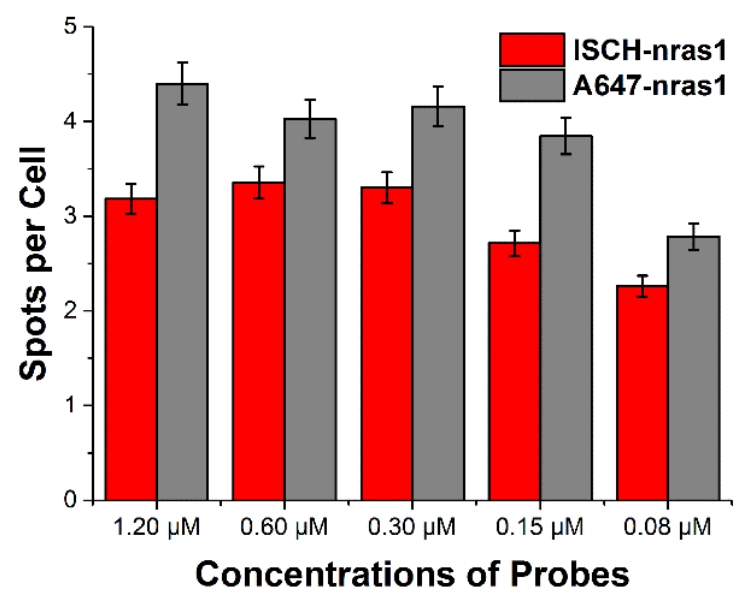

Figure S27. Quantification of spots inside cells transfected with G4T25 stained by various concentrations of A647-nras1 and ISCH-nras1. The fluorescence spots in cells were almost the same when concentration of ISCH-nras1 or A647-nras1 was above $0.3 \mu \mathrm{M}$. Thus, $0.3 \mu \mathrm{M}$ of ISCH-nras1 or A647-nras1 was used in the cell staining assays.

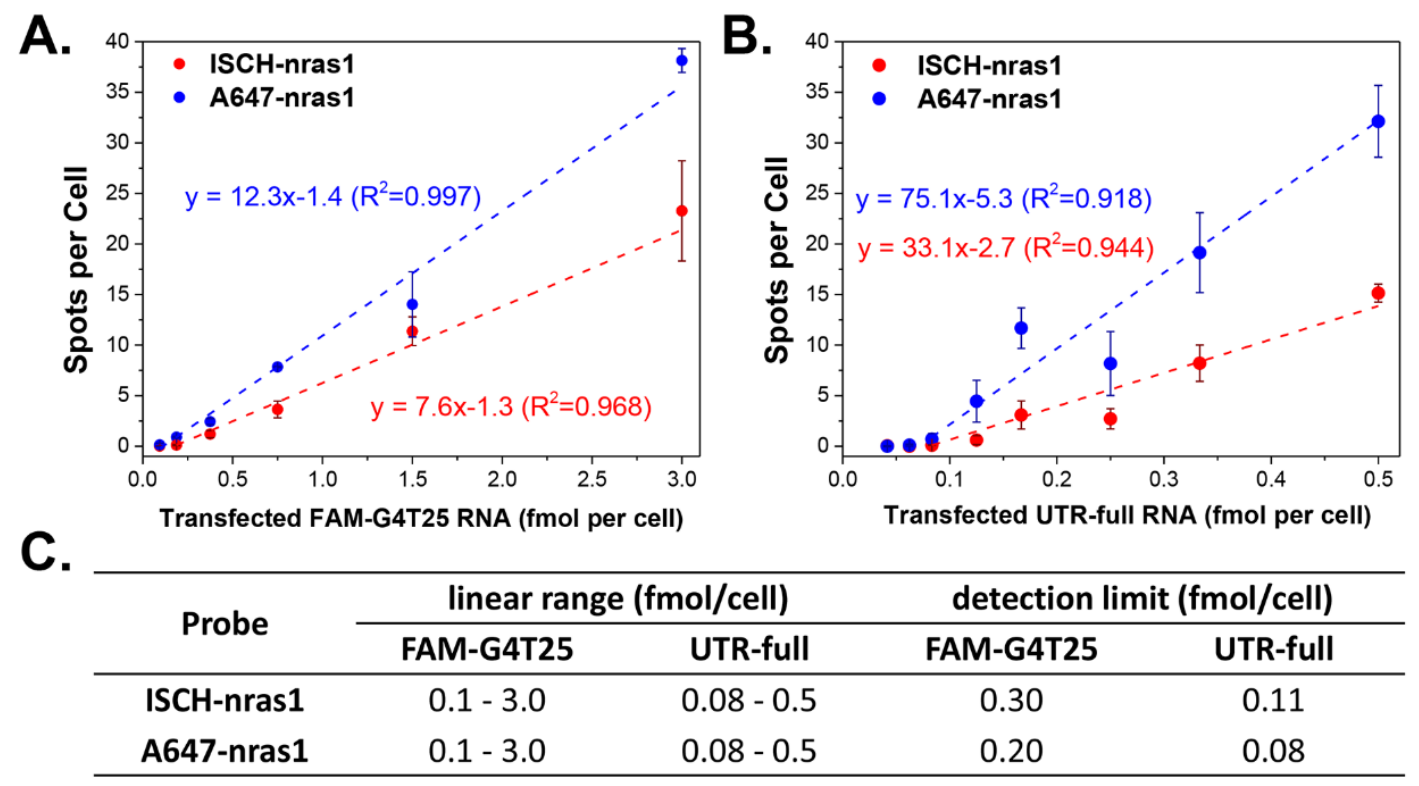

Figure S28. Quantification of ISCH-nras1 and A647-nras1 spots inside cells transfected with different amount of RNAs. (A) ISCH-nras1 and A647-nras1 spots per cell transfected with FAM-G4T25. (B) ISCH-nras1 and A647-nras1 spots per cell transfected with UTR-full. (C) The detection limits and linear ranges of ISCH-nras1 and A647-nras1 for the RNAs. The detection limit per cell was defined as the amount of RNAs that formed an easily detectable clear spot. The value was calculated on the basis of the linear fitting curve, which was derived from the linear range of ISCH-nras1 and A647-nras1 with different amount of transfected RNAs. 


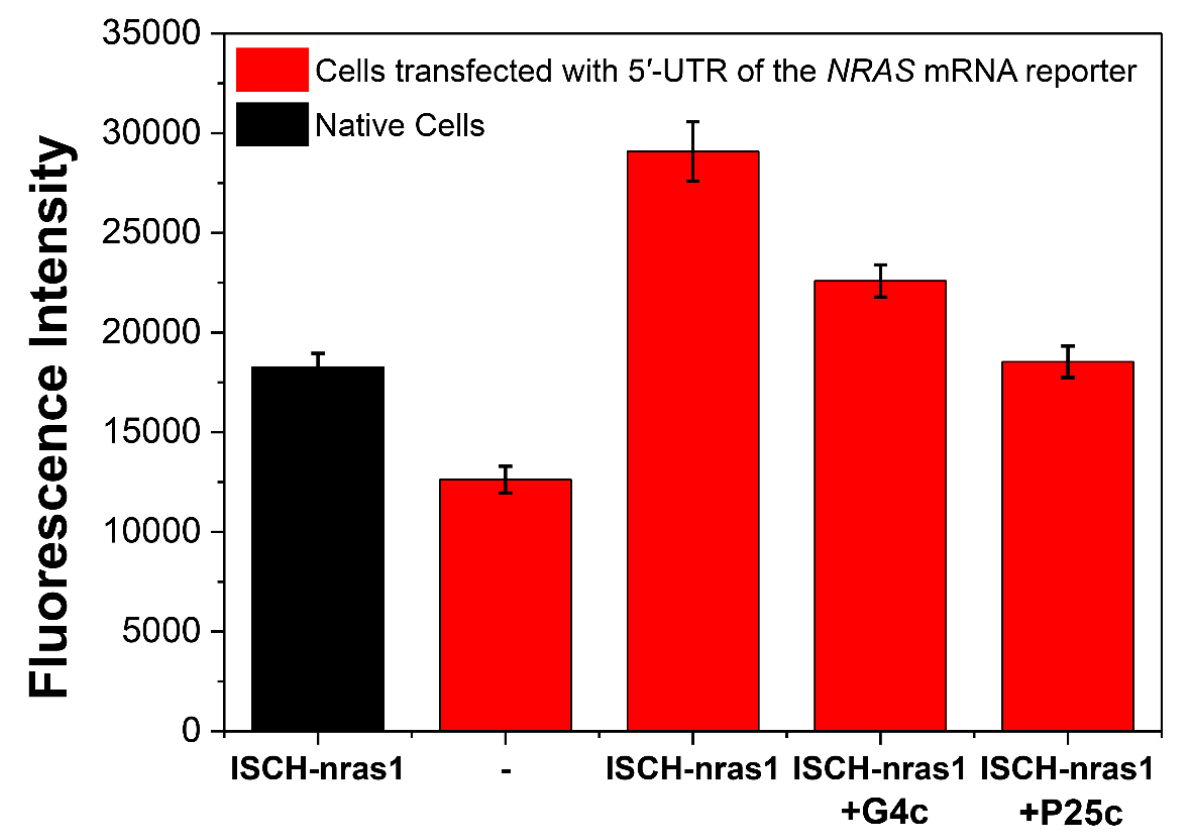

Figure S29. Quantification of the fluorescence intensity inside cells transfected with $5^{\prime}$-UTR of the NRAS mRNA reporter after treatment of ISCH-nras1 $(1 \mu \mathrm{M})$ with or without $\mathbf{G 4 c}(5 \mu \mathrm{M})$ and P25c $(5 \mu \mathrm{M})$ sequences using high-content imaging platform. The data were acquired from 10000 cells per sample and three parallel experiments were performed. Emission of native cells after treatment of ISCH-nras1 and emission of cells transfected with 5'-UTR of the NRAS mRNA reporter were shown as the background. As shown in the figure, enhanced fluorescence could be found in the cells transfected with the reporter after treatment of ISCH-nras1. Such original enhanced fluorescence signals evidently decreased by G4c or P25c treatment. G4c was the complementary strand to the G-rich sequence and P25c was the complementary strand to the tail sequence within the 5'-UTR of the NRAS mRNA. These findings are consistent with the results observed from the staining assays in which cells were directly transfected with RNAs. 

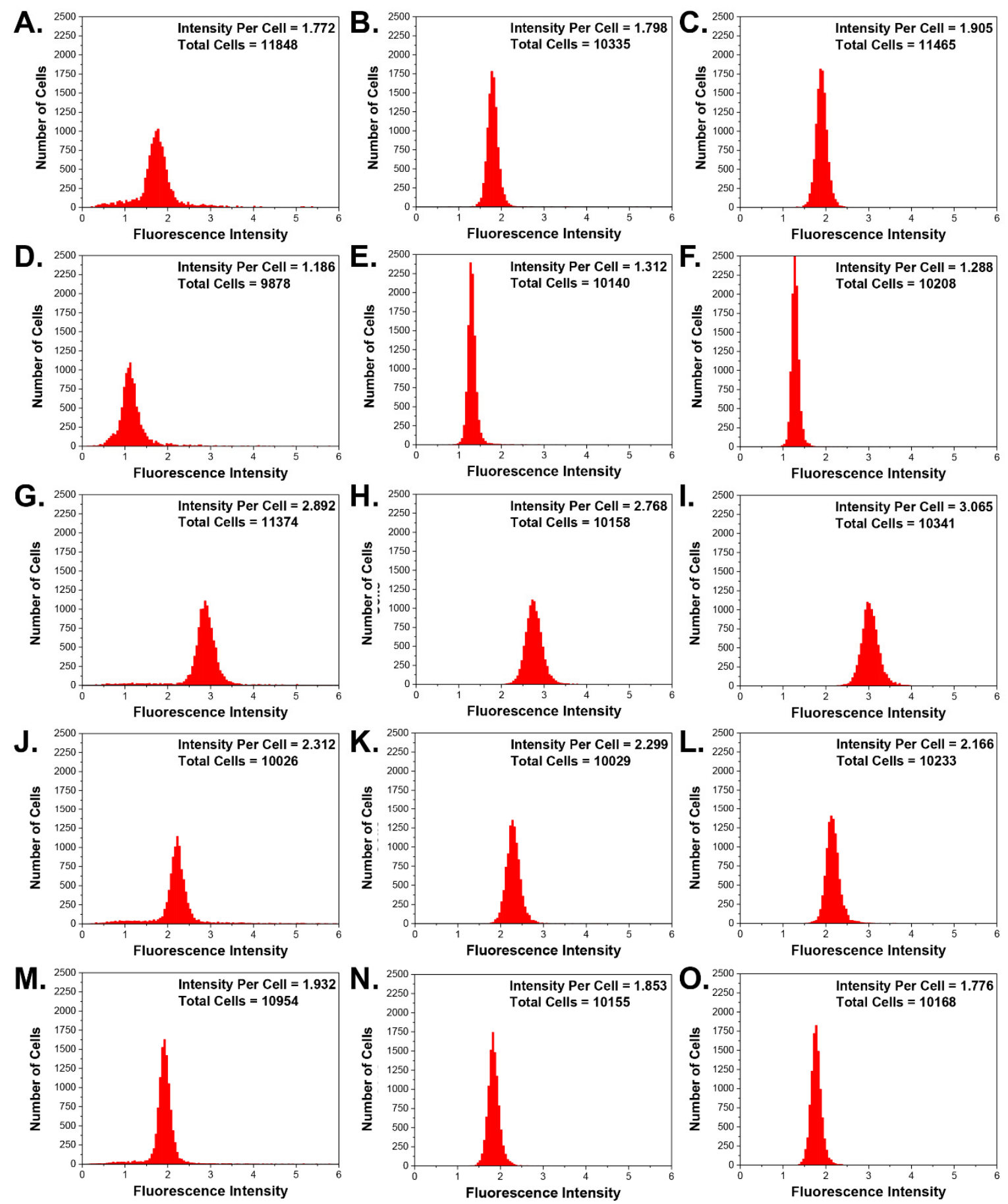

Figure S30. Histogram plotting of cell population versus corresponding fluorescence intensity quantified by high-content imaging platform. Each sample contained about 10000 cells and three parallel experiments were performed. The fluorescence intensity per cell in each sample was shown in the inner panel. (A, B, C) Histogram plotting for native cells after treatment of ISCH-nras1. (D, E, F) Histogram plotting for cells transfected with 5'-UTR of the NRAS mRNA reporter. (G, H, I) Histogram plotting for cells transfected with 5'-UTR of the $N R A S$ mRNA reporter after treatment of ISCH-nras1 $(1 \mu \mathrm{M}) .(\mathrm{J}, \mathrm{K}, \mathrm{L})$ Histogram plotting for cells transfected with 5'-UTR of the NRAS mRNA reporter after treatment of ISCH-nras1 $(1 \mu \mathrm{M})$ and $\mathbf{G 4 c}(5 \mu \mathrm{M})$. (M, N, O) Histogram plotting for cells transfected with $5^{\prime}$-UTR of the NRAS mRNA reporter after treatment of ISCHnras1 $(1 \mu \mathrm{M})$ and P25c $(5 \mu \mathrm{M})$. 


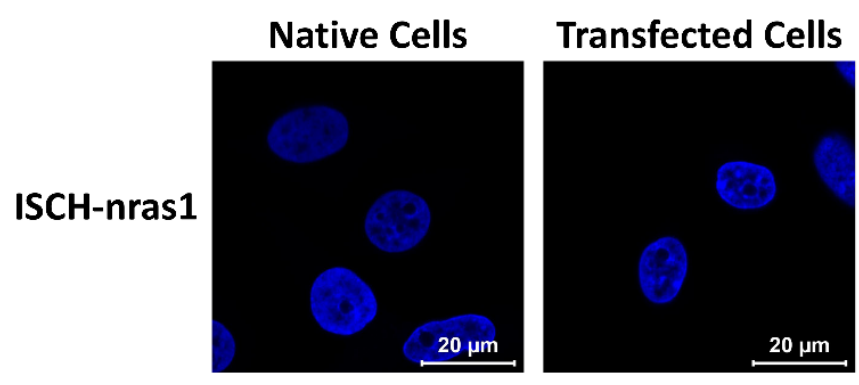

Figure S31. Confocal imaging of native cells and cells transfected with 5'-UTR of the NRAS mRNA reporter stained with ISCH-nras1.

\section{References}

(1) Hu, M. H.; Chen, S. B.; Guo, R. J.; Ou, T. M.; Huang, Z. S.; Tan, J. H. Analyst 2015, 140, 4616.

(2) Vorlickova, M.; Kejnovska, I.; Sagi, J.; Renciuk, D.; Bednarova, K.; Motlova, J.; Kypr, J. Methods 2012, 57,64 .

(3) Mergny, J. L.; Li, J.; Lacroix, L.; Amrane, S.; Chaires, J. B. Nucleic Acids Res. 2005, 33, e138.

(4) Dunn, K. W.; Kamocka, M. M.; McDonald, J. H. Am. J. Physiol. Cell Physiol. 2011, 300, C723. 